The standardized Five-Level Risk and Needs System is similar to comprehensive, status quo reports for communicating criminal recidivism risk

\author{
by \\ Meghan L. Garvey \\ A thesis submitted to the Faculty of Graduate and Postdoctoral Affairs in partial \\ fulfillment of the requirements for the degree of \\ Master of Arts \\ in \\ Psychology \\ Carleton University \\ Ottawa, Ontario
}

Meghan L. Garvey 2020@ 


\title{
TESTING A NEW NON-ARBITRARY SYSTEM FOR RISK COMMUNICATION
}

\begin{abstract}
The risk communication literature has shown mixed results about the most efficient way to communicate risk. In an attempt to standardize the way risk is communicated, Hanson, Bourgon and colleagues (2017) proposed the Five-Level Risk and Needs System. Despite the proposed benefits of the new system, the utility has yet to be thoroughly tested. The current study assessed whether utilizing the Five-Level System aids in the comprehension of risk and treatment amenability of a mock justice-involved individual. The study utilized a 3 x 2 design, manipulating risk level (low, moderate, high) and communication format (status quo, Five-Levels). Participants were asked to make decisions regarding parole, risk of recidivism, treatment amenability, among other risk, treatment, and understandability outcomes. Overall, limited support was found for communicating risk using the Five-Level System; however, there was evidence for improved consistency in risk perceptions, especially for participants presented with a moderate risk case. Findings suggested risk level was more salient than how risk was communicated.
\end{abstract}

Keywords: Five-Level Risk and Needs System; risk assessment; risk communication; risk 


\section{TESTING A NEW NON-ARBITRARY SYSTEM FOR RISK COMMUNICATION}

\section{Acknowledgements}

I would like to thank my advisor, Dr. Julie Blais for her guidance, supervision, and feedback throughout this process. I would also like to thank my committee members, Dr. Adelle Forth, Dr. Karl Hanson, and Dr. Michael Mopas for their time, dedication, and feedback in this process.

To my lab mates, Natasha², I'm so glad we could complete this journey together, thank you for your support, advice, and guidance.

To my friends and family, thank you for your love, kindness, support, for always being there for me, and participating in this study (I literally could not have done it without you).

Finally, to my best friend and partner, Joshua, you are a more caring and selfless person than I will ever be. Thank you for your unwavering support and belief in me. You inspire and motivate me every day to be better. Thank you for helping me through challenges, reading every draft, and doing everything first. I'm excited to tackle our next adventure together. 


\section{TESTING A NEW NON-ARBITRARY SYSTEM FOR RISK COMMUNICATION}

\section{Table of Contents}

The standardized Five-Level Risk and Needs System is similar to comprehensive, status quo reports for communicating criminal recidivism risk....................................... 1

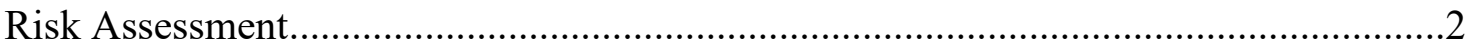

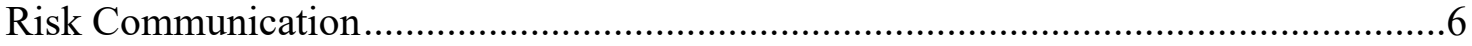

Limitations of Risk Communication Practices........................................................8

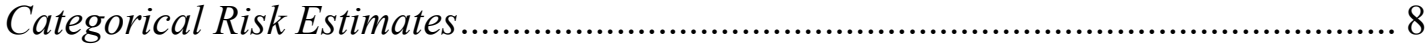

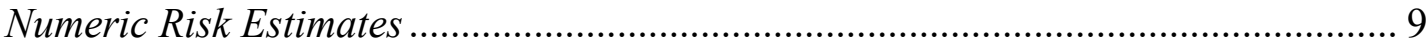

Comparing Risk Communication Strategies ..........................................................10

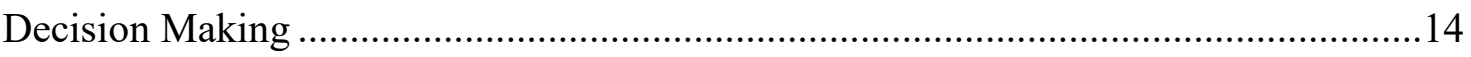

The Five-Level Risk and Needs System ....................................................... 17

The Five-Level System and Risk Decisions .........................................................23

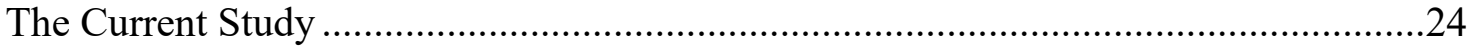

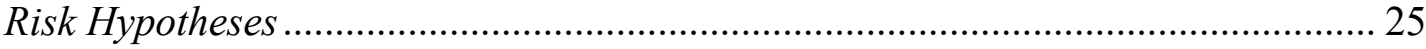

Treatment/ Management Relevant Hypotheses ..................................................... 26

Understandability/Importance Hypotheses ......................................................... 27

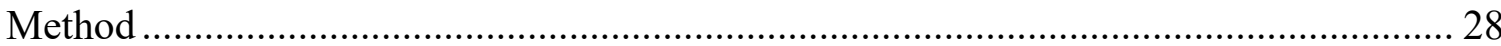

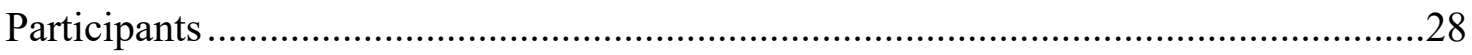

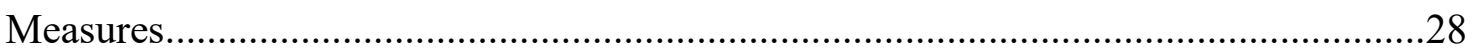

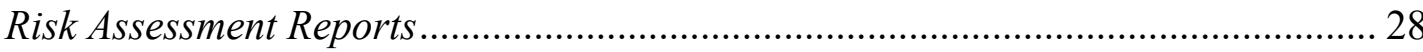

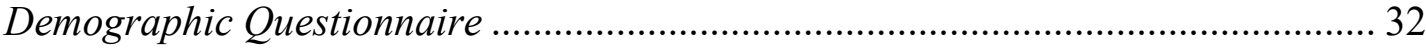

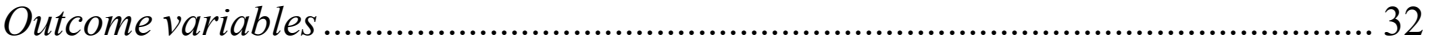

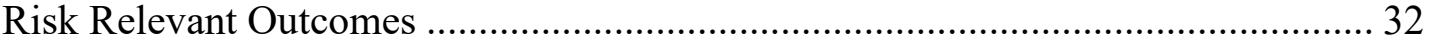

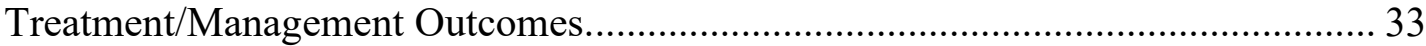

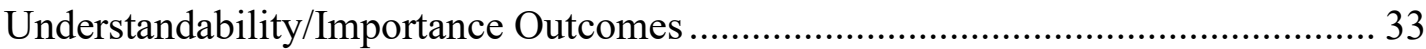

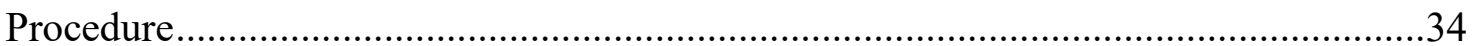

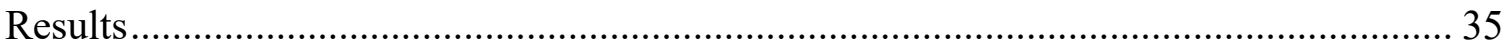

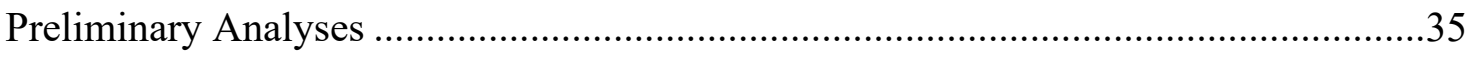

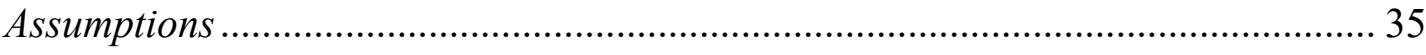

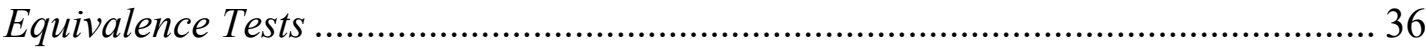

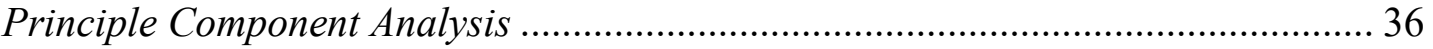

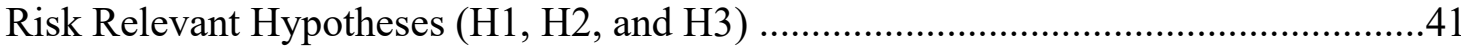

Parole Decision and Confidence ................................................................................ 41 


\section{TESTING A NEW NON-ARBITRARY SYSTEM FOR RISK COMMUNICATION}

Absolute Recidivism Risk and Likelihood of Recidivism ....................................... 43

Consistency in Categorical Risk Rating ............................................................ 46

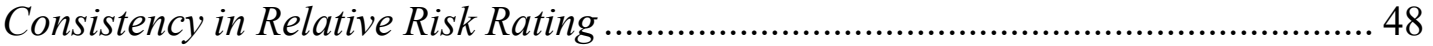

Treatment/Management Relevant Hypotheses (H4, H5, H6) .....................................49

Understandability/Importance Hypotheses (H7 and H8) .........................................50

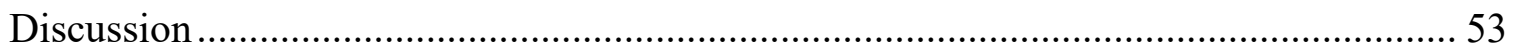

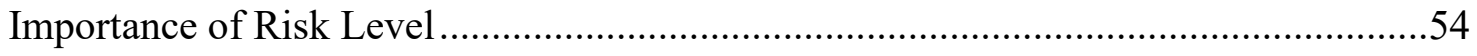

Importance of Risk Communication Format...........................................................55

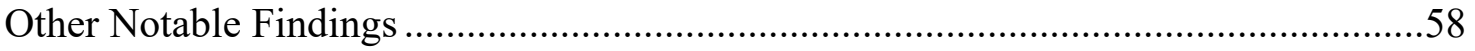

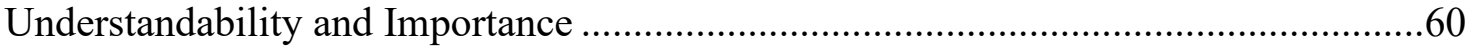

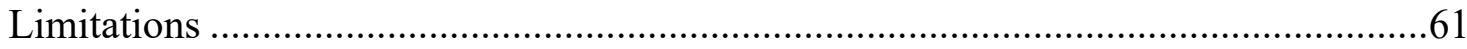

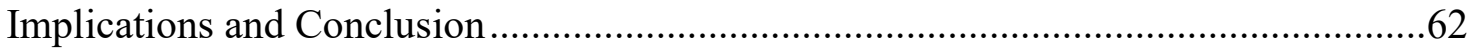

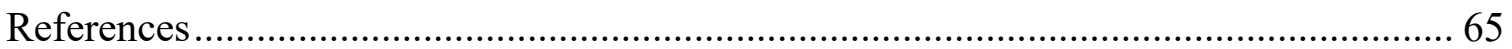




\section{TESTING A NEW NON-ARBITRARY SYSTEM FOR RISK COMMUNICATION}

\section{List of Tables}

Table 1. Description of Various Risk Studies.................................. 12

Table 2. The Five-Level Risk and Needs System..............................21

Table 3. Correlations of Treatment/Management Variables ......................37

Table 4. Rotated Factor Loadings of Treatment/Management Variables...........37

Table 5. Correlations of Decision Making Importance Variables..................38

Table 6. Rotated Factor Loadings for Decision Making Importance Variables... 39

Table 7. Participant Responses on All Outcomes .................................. 40

Table 8. Logistic Regression for Parole Decisions ..............................42

Table 9. Logistic Regression for Dichotomous Risk Decisions....................44

Table 10. Ranges of Responses Provided for Likelihood of Committing a New Crime Within Two Years...........................................................45

Table 11. Logistic Regression for Consistency in Risk Ratings..................47

Table 12. Logistic Regression for Relative Risk Ratings..........................49

Table 13. Logistic Regression for Enough Information Variables..................51 


\section{TESTING A NEW NON-ARBITRARY SYSTEM FOR RISK COMMUNICATION}

\section{List of Figures}

Figure 1. Interaction Plot of Granted Parole Decisions By Randomly Assigned Risk Level (Low, Moderate, High) and Separated by Communication Conditions (Status Quo vs. Five-Levels)...................................................4 42

Figure 2. Interaction Plot of Consistent Categorical Risk Decisions By Randomly Assigned Risk Level (Low, Moderate, High) and Separated by Communication Conditions (Status Quo vs. Five-Levels....

Figure 3. Consistency in Risk Ratings .....................................48 


\section{TESTING A NEW NON-ARBITRARY SYSTEM FOR RISK COMMUNICATION}

\section{List of Appendices}

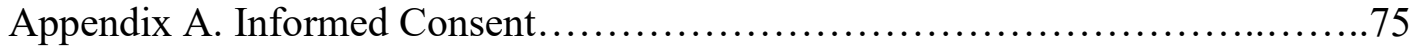

Appendix B. Mock Risk Assessments...................................... 77

Appendix C. Demographics, Validity Checks, and Outcome Variables............101

Appendix D. Recruitment Notice ........................................ 105

Appendix E. Varying Information Across Mock Risk Assessments................106 
The standardized Five-Level Risk and Needs System is similar to comprehensive, status quo reports for communicating criminal recidivism risk.

The past twenty-five years have seen an increase in risk assessment tools available for use in forensic settings (Singh et al., 2014). In assessing risk, one important component is the appropriate communication of risk-relevant information (e.g., risk posed, treatment amenability, etc.). The communication of risk can impact expert legal opinion, parole decisions, security level placements in prisons and forensic hospitals, treatment, and more (Viljoen et al., 2010). In acknowledgement of the practical implications of risk communication, there is a strong need to examine and promote the most effective ways of communicating or disseminating risk knowledge. Notwithstanding these aims, there are fundamental barriers in the literature impeding upon clear risk communication. Research has consistently shown both judges and laypeople prefer categorical descriptions of risk despite the fact that categorical communication can lead to an overestimation of risk, leading to higher conviction rates, or harsher sentences (Krauss et al., 2018; Scurich, 2018). Risk communicated in a frequency format (e.g., 1 in 10) has been shown to lead to lower likelihoods of commitment decisions than risk communicated in a probability format (e.g., 10\% chance), though both are numerically equal (Slovic et al., 2000). Both laypeople and judges have therefore been shown to misunderstand numeric presentations of risk.

Several proposals have been made in an attempt to better communicate risk due to the implications it can have on public safety and individual lives. Hanson and colleagues (2017) have put forth a new method, the Five-Level Risk and Needs System in an attempt to address current issues associated with risk communication. The Five-Level system 
goes beyond simply categorizing individuals as low, moderate, and high risk, by providing a more meaningful label, including estimates of recidivism risk, and a more complete profile of the individual being assessed. Each level (I-V) results in a nonarbitrary category, meaning the boundaries of each level is clearly defined. The levels coincide with a recidivism estimate, a correctional response, and a prognosis. The FiveLevel system encompasses several recommendations for more effective risk communication, including numerical risk estimates, and the identification of relevant risk factors and risk management strategies (Conroy \& Murrie, 2007).

The methodology that the Five-Level system proposes has the potential to standardize the way risk is communicated by providing meaningful categorical labels. Despite these proposed benefits, research is needed to evaluate whether utilizing the Five-Levels actually results in different decisions among laypeople. The current study therefore aims to assess whether the Five-Level System results in different decisions concerning risk, treatment, and management outcomes compared to the standard approach to communicating risk among a sample of laypeople.

\section{Risk Assessment}

Static and dynamic risk factors are characteristics of individuals and their circumstances that can lead to an increase of future criminal behaviour (Andrews \& Bonta, 2010). Static risk factors are historical factors that are unchanging, like an individual's age at first conviction. Dynamic risk factors are changeable, meaning they can be amended through intervention efforts to reduce an individual's risk of future offending. Some dynamic factors can also be characterized as criminogenic needs, reflecting that these risk factors have a clear association with offending and targeting 
these factors is imperative to reducing the likelihood of future criminal behaviour (Andrews et al., 1990). Examples of well-established criminogenic needs include antisocial attitudes, association with antisocial peers, and substance abuse. Dynamic factors can also include non-criminogenic needs; these factors do not play a role in the likelihood of criminal behaviour, but may still be important targets in treatment, such as mental or physical health concerns (Andrews et al., 1990). There has been a distinction made between dynamic risk factors and criminogenic needs, as Kraemer and colleagues (1997) suggest that dynamic risk factors are simply factors that can be changed, but that criminogenic needs are causal risk factors, or factors that when manipulated, can change an outcome (recidivism).

Over the past two decades researchers have examined the importance of combining different risk factors into risk assessment tools designed to predict the likelihood of criminal behaviour. The use of accurate and reliable risk assessment advances the proper functioning of the Criminal Justice System (CJS). Risk assessments are commonly used in sentencing decisions, parole hearings, classification hearings, and security placements (Viljoen, et al., 2010). These decisions can have important implications on both the individual being assessed and to the general population, as many of these decisions concern public safety (Andrews \& Bonta, 2010).

Several generations of risk assessments have been used to describe the practice of risk assessment throughout the years. The earliest generation of risk assessment did not rely on empirically validated risk factors, instead relying on unstructured professional judgement, or a gut instinct (Andrews \& Bonta, 2010). This method of predicting risk has fallen mostly out of favour as prediction rates based on clinical judgment are often no 
better than chance (Ægisdóttir et al., 2006). An updated version of first-generation assessments includes structured professional judgement (SPJ) measures, which rely on the presence or absence of empirically relevant risk factors. However, there are no set rules for combining total scores as SPJs do not provide a numerical probability for the risk of recidivism, and ultimately professionals make the final decision about an individual's risk level based on professional judgment (Andrews et al., 2006).

As more nuanced tools were developed, the ability to more accurately predict risk increased. Second-generation risk tools are considered to be actuarial and rely on empirically valid static and unchanging risk factors. Actuarial instruments are created with a statistical basis where items are scored numerically and summed to produce a total score (Andrews, et al., 2006). Total scores are associated with recidivism estimates and are then often interpreted with a categorical risk ranking (e.g., low, moderate, or high). Although actuarial measures have been shown to be more predictive than unstructured professional judgement (Grove et al., 2000), many second-generation assessments are not founded in a theoretical basis and items are selected due to their association with recidivism (Andrews et al., 2006).

Newer generations of risk assessments incorporate both static and dynamic risk factors, while also having a basis in theory (Andrews et al., 2006). Third-generation assessments, like the Level of Service Inventory-Revised (LSI-R; Andrews \& Bonta, 1995), measure client needs as well as risk (Andrews et al., 2006). Third-generation measures highlight the utility of incorporating both static and dynamic risk factors, as a more precise summation of the individual's likelihood of recidivism. The fourth and newest generation of risk assessment integrates case management with risk and needs 
assessment (Andrews \& Bonta, 2010). The goal of the newest generation of risk assessment is to strengthen adherence to the principles of effective treatment while facilitating clinical supervision in order to prevent recidivism (Andrews et al., 2006).

The newest generation of risk assessment relies heavily on the Risk, Needs, Responsivity (RNR) model put forth by Andrews and colleagues (1990). RNR defines the key components of rehabilitation for individuals involved in the CJS (Andrews et al., 1990). The first principle, risk, guides who to treat, suggesting that it is vital to match the level of program intensity to the client's risk level (e.g., higher intensity treatment to higher risk clients). The needs principle guides what to target in treatment, including an individual's criminogenic needs (e.g., pro-criminal attitudes). These needs are the most relevant factors to target to prevent the likelihood of future criminal behaviour. The responsivity principle suggests how best to treat a justice-involved individual, by matching the style and method of intervention to the client's abilities. The responsivity factor encompasses both general responsivity (e.g., using cognitive behaviour therapy) and specific responsivity (e.g., adapting the cognitive behavioural therapy to meet specific client characteristics; Bonta \& Andrews, 2017).

Research has consistently supported interventions based upon the RNR model, with interventions following these principles having been shown to be effective for numerous populations of justice-involved individuals (e.g., those who commit general offences, those who commit violent offences, and those who commit sexual offences; Andrews et al., 1990; Dowden \& Andrews, 1999a,b, 2000, 2003; Hanson et al., 2009). Several studies have shown that programs following RNR principles show incremental effects; the more principles they adhere to, the better the outcome (Bonta \& Andrews, 
2017). Though RNR is not the only treatment model (e.g., Good Lives Model; see Ward \& Stewart, 2003), it is the most widely adopted (Bonta \& Andrews, 2017).

\section{Risk Communication}

Due to the broad use of risk assessment and the implications of the associated decisions, it is imperative to communicate risk effectively to decision makers. In a study examining clinical practices for risk assessment, almost all clinicians surveyed used structured risk assessment tools, rather than unstructured professional judgement, to assess the likelihood of future violence or reoffending (Viljoen et al., 2010). Approximately $75 \%$ of clinicians used a standard, or widely used, tool for adult justiceinvolved individuals, with very few clinicians indicating they never used a standard tool. The most commonly used tools for justice-involved adults included the Psychopathy Checklist-Revised (PCL-R; Hare, 2003), the Historical and Clinical Risk Management-20 (HCR-20; Webster et al., 1997), and the Minnesota Multiphasic Personality Inventory (MMPI-II; Hathaway \& McKinley, 1989; despite the fact that this is not a risk measure). Younger clinicians were more likely than older clinicians (over age 47) to use a standard risk assessment and to make recommendations about treatment targets. The majority of clinicians reported that they commonly communicate risk in categorical terms (e.g., low, medium, or high risk), with only $13 \%$ reporting they prefer to communicate risk in terms of a probability (e.g., 13\% chance of reoffending; Viljoen et al., 2010). Few clinicians indicated that they discuss possible targets or timelines for offending, the seriousness of future offending, or give a level of confidence in their judgements.

Blais and Forth (2014) further examined the content of risk assessment reports by examining 120 reports provided by experts in the context of Dangerous Offender 
hearings in Canada. Experts provided information on risk management (79\%) and discussed risk factors beyond those included in the risk assessment scales $(88.5 \%)$, while it was less likely that the reports mentioned the likelihood of future offending (34.6\%). The average number of risk tools used per assessment was three, and these tools were used to assess risk, psychopathy, and mental health. Less than half of the assessments contained information on dynamic risk factors while providing very little information about implications of risk scores, risk management, or treatment amenability. Experts were most likely to communicate their findings of risk with a categorical message (e.g. low, moderate, high; Blais \& Forth, 2014).

Among forensic clinicians utilizing risk assessment tools, categorical language has been shown to be the preferred and most frequently used method of risk communication (Doyle et al., 2011; Heilbrun et al., 2004; Heilbrun et al., 1999; Jung et al., 2013). For example, among an international sample of 1520 forensic evaluators, roughly $85 \%$ reported using categorical terms to communicate violence risk outcomes (Singh et al., 2014). In addition to clinicians, judges have also been found to prefer categorical language compared to probabilistic and frequency estimates (Dolores \& Redding, 2009). This finding was replicated in a large sample of judges who found categorical risk prediction messages to be more probative than probabilistic or frequency messages (Evans \& Salekin, 2014). However, Storey and colleagues (2013) found judges to prefer that evaluators provide them with probability and severity of recidivism as well as a worst-case scenario. Discrepant findings such as these highlight that even among the same group of professionals, differences in preferences of risk communication are evident. 


\section{Limitations of Risk Communication Practices}

\section{Categorical Risk Estimates}

Numerous issues arise from using categorical language to communicate risk, the main issue being that there is no consensus on what the nonnumeric categories represent, as there are no set boundaries as to what each risk level equates to numerically (Scurich, 2018). Without this consensus, issues arise on how to define 'high risk' versus 'low risk'. When a sample of 60 forensic clinicians was asked to discriminate between low, medium, and high risk on a scale of 1-100, for a violent individual, the 'high risk' category ranged from $38-100 \%$ while the 'low risk' category ranged from $8-54 \%$ (Hilton et al., 2008). Similarly, Mills and Kroner (2006) asked 52 psychologists what 'high risk' reflects for individuals committing violent and sexual offences, finding the mean risk response to be $63.5 \%$ with a standard deviation of $23.3 \%$, indicating a large amount of variability. Evans and Salekin (2016) asked a sample of judges to fill in the blank in the following sentence regarding a mock civil commitment decision: "the term high risk indicates that individual has a ___ percent chance of committing a violent behaviour in the near future" (p. 154). Responses ranged from 5-100\% (Evans \& Salekin, 2016). These large variations in the boundaries assigned to categorical risk levels can lead to individuals being placed in the same risk category who have drastically different risk levels (Scurich, 2018).

Research has also examined the effect of risk communication on laypeople. In a mock Sexually Violent Predator (SVP) commitment hearing, jurors presented with a categorical estimate were more likely to commit 'high risk' individuals than individuals given a probabilistic estimate (e.g., 13\% likely to reoffend in 10 years) that equated to a 'high risk' decision on the Static-99R (Krauss et al., 2018). Commitment decisions were 
found to increase as categorical risk level increased, while these results were not replicated when jurors were presented with probabilistic estimates. Categorical risk estimates may lead jurors to overestimate risk and therefore be more likely to commit individuals (Krauss et al., 2018). Presenting risk in a probabilistic format may provide the base rates necessary for jurors to make more accurate commitment decisions (Krauss et al., 2018). Scurich (2018) goes further suggesting that risk be solely communicated numerically, as forensic science in general is moving away from categorical statements and estimates.

\section{Numeric Risk Estimates}

Despite the recommendation for the use of numerical estimates when communicating risk, this practice can also have limitations. Slovic, Monahan, and MacGregor (2000) found that communicating risk through frequencies (e.g., 1 in 10) led to a lower likelihood of commitment judgements than risk communicated in a probability (e.g., 10\% chance). Scurich and John (2011) used a sample of undergraduate students to assess whether decision makers were biased by the way in which risk was framed. Participants read six case studies and had to decide whether or not to authorize a 14-day involuntary psychiatric commitment of an individual with a mental illness who could pose a danger to themselves or others (yes or no). Risk was framed as either the probability of the event occurring or the probability of the event not occurring (e.g., there is a $26 \%$ change of violent recidivism vs. a $74 \%$ chance of no violence). Results indicated that when risk was framed as a probability of violence, this led to more conservative (e.g., higher) commitment decisions (Scurich \& John, 2011). Framing risk as a probability of violence seems to bias objective actuarial instruments (Scurich \& John, 
2011). In a similar study, Monahan and Silver (2003) found that just an $8 \%$ probability of violence was deemed dangerous enough to warrant a commitment decision. Discrepant risk judgements and interpretations such as these highlight that the way risk is framed can bias decision outcomes (Scurich \& John, 2011).

\section{Comparing Risk Communication Strategies}

Several studies have directly compared categorical and numerical risk communication strategies. Varela and colleagues (2014) compared risk communication formats on a sample of laypersons' perceptions of an individual who committed a sexual offence. Using Static-99 scores, the researchers presented a high or low score with a varied risk communication format (categorical - low vs. high; risk estimate $-9.4 \%$ vs. $31.2 \%$ of men who score similarly would reoffend within 5 years; and relative risk $-3 / 4$ the recidivism rate vs. 2.91 times the recidivism rate of a typical individual who commits sexual offences). Different risk communication formats were found to lead laypersons to different conclusions regarding recidivism risk. For example, risk ratings for the high risk individual in the categorical condition were significantly higher than the relative risk condition (Varela et al., 2014). Similarly, in Krauss and colleague's (2018) study, mock jurors were asked to make a decision on an SVP commitment. The researchers presented risk either categorically (low, low-moderate, moderate-high, high) or probabilistically $(13 \%, 21 \%, 30 \%, 43 \%)$, consistent with the estimates from the Static-99. SVP commitment decisions increased when assessments contained a categorical risk communication method rather than a numerical (probabilistic) one (Krauss, 2018).

In order to further the research regarding laypeople and risk communication format, Batastini and colleagues (2018) attempted to determine whether the format risk 
was presented in would influence perceptions of an individual's likelihood for violence (including numerical, categorical, and management information). Numerical data communication was associated with lower levels of appraised risk, but only when asked for a probability from $0-100 \%$. Overall, participants overestimated risk beyond what the expert reported for both seven- and ten-year follow-ups (Batastini et al., 2018).

Following-up Study 1 Batastini and colleagues (2018) examined the use of additive strategies that could enhance laypersons attention to the use of base rates (i.e., how often a phenomenon occurs in a certain population; Batastini et al., 2018) and visual aids in risk communication in Study 2. A sample of mock jurors were randomly assigned to one of three conditions regarding base rates: no explanation, written narrative only, or written and visual explanation. Participants were asked to complete the same measures used in Study 1 . There were no significant differences found between the groups on differing explanations of base rates and visual aids. The findings suggest there is a tendency in laypersons to ignore information about base rates.

In order to verify the findings of their previous study (2018), Batastini and colleagues (2019) hypothesized that with the presentation of numerical data, the inclusion of base rate explanations with a visual aid would be associated with more congruence with the information provided by the expert. However, visual aids failed to provide support for the explanation of base rates. Overall, risk management information and categorical representation of risk were associated with higher ratings of risk. Though previously risk management information was found to aid judges in their decisions (Dolores \& Redding, 2009), this study found the inclusion led to more severe overestimations of risk (Batastini et al., 2019). 
The findings of the aforementioned studies are summarized in Table 1. Overall, the limitations in the risk communication literature cannot be overlooked. Categorical risk communication has consistently been shown to be the preferred communication format by professionals and laypeople; however, it can result in more conservative (or higher) risk decisions. Research also suggests that risk management and categorical presentations of risk without actuarial data produce higher risk estimates, and that the inclusion of visual aids to contextualize base rates seems to be ineffective. Numerical presentations by experts in the courts may not be understood by laypersons and it may be beneficial to provide data driven examples to support a categorical risk estimate (Batastini et al., 2019). The research also suggests that in accordance with findings from cognitive psychology, laypeople tend to ignore base rates when making decisions. Based on this result, more traditional decision-making literature has the potential to provide much needed insight into risk communication findings.

\section{Table 1}

\section{Description of Various Risk Studies}

\begin{tabular}{lllll}
\hline Study & Sample & Manipulation & Outcome Variable(s) & Main Findings \\
\hline Batastini & Study 1: self- & Study 1: 4 & Likelihood of & Study 1: numerical data \\
et al., & reported & conditions: risk & violence (0-100\%), & was associated with lower \\
2018 & jurors (aged & actuarial, risk & perceived & levels of appraised risk \\
& 18 years or & categorical, risk & dangerousness scale & but only when asked 0- \\
& older) from & management, and & (PDS), social distance & 100\%. Still overestimated \\
Qualtrics & risk hybrid & scale (SDS) & risk beyond what expert \\
& Study 2: 199 & (categorical and & Asked what category & reported for 7 and 10 year \\
ftudents from & management) & of risk they believed & follow ups \\
& introductory & Study 2: base rates, & represented defendant & Study 2: risk ratings were \\
psychology & 3 conditions: no & (low, moderately low, not affected by info about \\
& medium, moderately & base rates - tendency to \\
& course & explanation, & high, high) & visual representations \\
& & written & & were not helpful - similar \\
& & explanation, & to Hilton et al., 2017
\end{tabular}




\begin{tabular}{|c|c|c|c|c|}
\hline Study & Sample & Manipulation & Outcome Variable(s) & Main Findings \\
\hline $\begin{array}{l}\text { Batastini } \\
\text { et al., } \\
2019\end{array}$ & $\begin{array}{l}155 \text { self- } \\
\text { reported } \\
\text { jurors from } \\
\text { Qualtrics }\end{array}$ & $\begin{array}{l}6 \text { conditions: } \\
\text { Risk management } \\
\text { Numerical without } \\
\text { base rate } \\
\text { Numerical with } \\
\text { base rate } \\
\text { Categorical risk } \\
\text { Hybrid; categorical } \\
+ \text { numerical + } \\
\text { management } \\
\text { Hybrid with base } \\
\text { rate; categorical + } \\
\text { numerical + } \\
\text { management }+ \\
\text { base rate }\end{array}$ & $\begin{array}{l}\text { Rate recidivism } \\
\text { likelihood } 0-100 \% \\
\text { Ordinal risk - low, } \\
\text { moderate, high } \\
\text { How likely Mr. Parks } \\
\text { was to commit } 5 \\
\text { other violent acts } \\
\text { (murder, physical } \\
\text { assault, robbery, } \\
\text { sexual assault, child } \\
\text { molestation) } \\
\text { Sentence if found } \\
\text { guilty (ranged from } \\
\text { less than } 10 \text { years to } \\
\text { death penalty) } \\
\text { How comfortable } \\
\text { would participants be } \\
\text { if one day he was } \\
\text { released back into the } \\
\text { community (0-100) }\end{array}$ & $\begin{array}{l}\text { Risk management and } \\
\text { categorical formats } \\
\text { without actuarial data } \\
\text { produce higher estimates } \\
\text { of risk } \\
\text { Using visuals aids to } \\
\text { contextualize base rates } \\
\text { seems to be unnecessary } \\
\text { in communicating } \\
\text { actuarial data } \\
\text { Laypersons follow expert } \\
\text { testimony regarding } \\
\text { estimates of risk, but } \\
\text { other factors may have a } \\
\text { greater influence on their } \\
\text { decision making (crime } \\
\text { severity) }\end{array}$ \\
\hline $\begin{array}{l}\text { Krauss et } \\
\text { al., } 2018\end{array}$ & $\begin{array}{l}432 \text { USA } \\
\text { residents } \\
\text { from MTurk }\end{array}$ & $\begin{array}{l}\text { Categorical v. } \\
\text { probabilistic } \\
\text { outcomes based on } \\
\text { the Static-99 }\end{array}$ & $\begin{array}{l}\text { SVP commitment in } \\
\text { mock juror SVP } \\
\text { hearings }\end{array}$ & $\begin{array}{l}\text { Categorical condition - } \\
\text { commitment decisions } \\
\text { significantly dependent } \\
\text { on risk level } \\
\text { Probabilistic condition - } \\
\text { commitment decisions not } \\
\text { significantly dependent } \\
\text { on risk level }\end{array}$ \\
\hline $\begin{array}{l}\text { Scurich } \\
\text { \& John, } \\
2011\end{array}$ & $\begin{array}{l}303 \\
\text { university } \\
\text { undergraduate } \\
\text { students } \\
\text { acting as } \\
\text { mock judges }\end{array}$ & $\begin{array}{l}6 \text { cases, made } \\
\text { commitment } \\
\text { decision on each of } \\
\text { them } \\
\text { Framed as either: } \\
26 \% \text { chance of } \\
\text { violence occurring, } \\
\text { or } 74 \% \text { chance of } \\
\text { violence not } \\
\text { occurring }\end{array}$ & $\begin{array}{l}\text { Decide to authorize } \\
\text { 14-day involuntary } \\
\text { psychiatric } \\
\text { commitment or not } \\
\text { How likely to release } \\
\text { on 6-point scale }\end{array}$ & $\begin{array}{l}\text { Decision to commit or not } \\
\text { depends largely on how } \\
\text { risk is framed - when } \\
\text { framed as a probability of } \\
\text { no violence - less } \\
\text { commitment than when } \\
\text { risk is framed in a } \\
\text { probability of violence - } \\
\text { especially in moderate } \\
\text { risk individuals }\end{array}$ \\
\hline
\end{tabular}




\begin{tabular}{|c|c|c|c|c|}
\hline Study & Sample & Manipulation & Outcome Variable(s) & Main Findings \\
\hline $\begin{array}{l}\text { Varela et } \\
\text { al., } 2014\end{array}$ & $\begin{array}{l}211 \text { adults } \\
\text { called for jury } \\
\text { duty }\end{array}$ & $\begin{array}{l}6 \text { conditions: high } \\
\text { v. low x } \\
\text { categorical, } \\
\text { relative risk, risk } \\
\text { estimate }\end{array}$ & $\begin{array}{l}\text { Likelihood to commit } \\
\text { a new sexual offense } \\
\text { within } 5 \text { years, } \\
\text { dangerousness to } \\
\text { community members, } \\
\text { and support for the } \\
\text { use of the most strict } \\
\text { and expensive } \\
\text { supervision strategies } \\
\text { (all rated from 1-6). } \\
\text { Two dichotomous } \\
\text { items: Less likely or } \\
\text { more likely than most } \\
\text { justice-involved } \\
\text { individuals to commit } \\
\text { another offense. } \\
\text { Would they or would } \\
\text { they not commit a } \\
\text { new sex offense in } \\
\text { the next } 5 \text { years. } \\
\text { Importance of Static- } \\
99 \text { results (1-6) } \\
\text { Easy to understand } \\
\text { Static-99 results? } \\
\text { (easy, somewhat } \\
\text { difficult, very } \\
\text { difficult) }\end{array}$ & $\begin{array}{l}\text { When the individual had a } \\
\text { high Static-99R score, } \\
\text { participants rated him as } \\
\text { more dangerous and } \\
\text { likely to reoffend when } \\
\text { the risk communication } \\
\text { included a categorical } \\
\text { message than a numerical } \\
\text { message }\end{array}$ \\
\hline
\end{tabular}

\section{Decision Making}

Drawing from traditional decision-making literature may help researchers

understand the results of the aforementioned studies. Tversky and Kahneman (1973) found that people's decision-making capabilities are often prone to numerous errors that are a result of mental shortcuts, called heuristics. These heuristics can aid in decisionmaking when solutions are not readily available, and can therefore make decisions easier, but can also result in errors. Tversky and Kahneman (1974) outline three main heuristics 
that could prove useful in understanding forensic decision making. The representativeness heuristic is a mental shortcut that is used when the subjective probability of an event is estimated based on its similarity to a presumably related event (Tversky \& Kahneman, 1974). Research has suggested that individuals select an outcome that is most representative of an input (Tversky \& Kahneman, 1974). In forensic contexts, this heuristic could explain base rate neglect demonstrated in the previous studies (Batastini et al., 2018, 2019) as individuals may judge the outcome's likelihood without actually considering the probability that the event will occur (Tversky \& Kahneman, 1974; Neal \& Grisso, 2014). For example, when participants were given a neutral description of a person and told that $70 \%$ of the individuals are engineers and $30 \%$ are lawyers, most participants said there was a 50\% chance the individual was either an engineer or lawyer (Tversky \& Kahneman, 1974). Studies like this and others have shown that laypeople simply ignore base rate information and instead focus on descriptions and case specific information. Laypeople only attend to base rates when case information is not provided.

The second heuristic explained by Tversky and Kahneman (1974) is the availability heuristic. This occurs when an individual judges the probability of an event occurring by which other instances can easily be recalled. Biases can occur due to several reasons, including the salience of an event (e.g., recent occurrences are more likely to be recalled), the imaginability of an event (e.g., risk can be underestimated when possible factors are not considered), and the illusion that events are correlated (e.g., strong associates will be judged to have occurred together more frequently; Tversky \& Kahneman, 1974). This heuristic is associated with confirmation bias or looking for data 
that supports your own biases and ignoring or not doing anything to refute them (Neal \& Grisso, 2014). In forensic settings, information about the severity of the crime (a factor that is unrelated to future risk) may lead decision makers to only focus on information that confirms their impressions of the individual as violent while ignoring mitigating factors presented in the risk assessment report. Furthermore, when assessing risk for violence, laypeople may overestimate the risk for future violence because of depictions seen on the news or in popular media as these would be most easily recalled.

The third heuristic discussed is anchoring. This occurs when information provided first (anchor) is more influential than information provided later (Tversky \& Kahneman, 1974; Neal \& Grisso, 2014). This can be problematic in decision making for laypeople and clinicians, as a negative first impression of an individual could override all subsequent information. For example, in forensic contexts, information about the client's index offence and criminal history could anchor opinions if presented earlier in the risk assessment report. This could lead to decision makers giving less weight to information provided later such as treatment progress and management strategies. This would result in a general overestimation of the client's risk. This may also explain why decision makers may give more weight to information that is unrelated to risk (e.g., offence severity) if it is presented earlier in the report while ignoring information from risk assessment scales, if that information is presented later.

These heuristics indicate that there are many reasons as to why laypeople and decision makers may misunderstand information related to the estimation of risk (i.e., base rate neglect), may be influenced by biased or sensationalized depictions of risk for violence in the media, or anchor their opinion about risk on details that are irrelevant 
while ignoring important variables, depending on the order of presentation. Researchers should therefore be aware of the common errors that individuals make when making decisions and strive to communicate risk information in a way that minimizes these biases (Neal \& Grisso, 2014). Researchers have suggested the use of actuarial measures to override several heuristics, as they can increase confidence in decisions and remove subjectivity (Murray \& Thomson, 2010). It has also been argued that when professionals are made aware of biases that can occur, they improve in accuracy and quality of their risk assessments (Borum et al., 1993; Elbogen, 2002). It is possible that risk communication that provides an actuarial assessment, base rate information, and is presented clearly may override certain biases, producing more accurate or consistent risk decisions.

\section{The Five-Level Risk and Needs System}

Given the limitations associated with current risk communication practices, Hanson and colleagues (2017) have put forth a Five-Level Risk and Needs System that goes beyond categorizing individuals based solely on probabilities and categorical risk levels. The overall goal of the Five-Level system is to have confidence in knowing what risk categories mean (non-arbitrary) regardless of what risk instrument is used while incorporating a more complete picture of an individual's likelihood for recidivism. The

Five-Level system was derived based on the recidivism risk for general offences. Beyond providing a numerical indication of recidivism risk (percentage of risk over two years), the Five-Levels include information on criminogenic and non-criminogenic needs which fall into three domains: psychological, interpersonal, and lifestyle. The psychological domain includes cognitive, emotional, and behavioural features that have been 
empirically linked to reoffending. The interpersonal domain comprises intimate, family, and peer relationships, and if an individual supports pro-social or pro-criminal behaviour. The lifestyle domain encompasses employment, education, housing, leisure activities, and substance use. Beyond this, the Five-Levels aim to better support the implementation of RNR principles by including corresponding risk of recidivism over two years (percentage), a correctional response, and an overall prognosis should the client receive appropriate rehabilitation efforts. By being placed within one of the five levels, the individual can have a more targeted treatment plan with better implementation of RNR principles, which should help to lower their overall risk for reoffending.

The Five-Levels are numbered with roman numerals without the use of categorical descriptors. The first level (Level I) indicates the lowest likelihood for recidivism (less than $5 \%$ over two years), while Level V indicates the highest $(85 \%$ or higher). The first two levels are marked by lower risk individuals; for example, individuals in levels I and II are expected to have few, if any, criminogenic and noncriminogenic needs. These individuals have known strengths and resources and would respond to interventions or services offered to them. Custodial sentences would not benefit individuals in either level and could in fact worsen outcomes. Level I individuals are expected to desist from criminal behaviour without a correctional intervention; their risk of reoffending is roughly $1-2 \%$ per year and corresponds to no more than that of a spontaneous first-time offence committed by someone without a criminal record.

Although Level II individuals are also expected to desist from criminal behaviour once they undergo an appropriate correctional response, their two-year recidivism rate is 
expected to be between 5-30\% with the average two-year reoffence rate at 19\% (Hanson, Bourgon, et al., 2017).

Individuals in Level III are considered to be average risk. They will have multiple criminogenic needs that range in severity in all three domains and may have one or two criminogenic needs that are the driving force behind their criminal behaviour. These individuals will likely have non-criminogenic needs, and, although they are expected to have resources and strengths, they may have barriers which impact access to those resources, such as mental health concerns (Hanson, Bourgon, et al., 2017). Custody would be appropriate in the short term for many of these individuals and with evidencebased interventions a significant reduction in criminal behaviour would be expected.

The highest levels of risk include Levels IV and V. While Level IV individuals have many criminogenic and non-criminogenic needs across all three domains, Level V is associated with the most severe needs. Individuals in the higher levels have severe barriers to accessing strengths and resources, if these resources are present at all. Secure custodial sentences are appropriate for both levels, while targeting their needs through intensive evidence-based interventions. With needs being targeted, individuals in Level IV could see a reduction in recidivism risk, while individuals in Level V may see a gradual decline in recidivism over many decades. Both levels require a high degree of supervision and continued programming, if released into the community (Hanson, Bourgon, et al., 2017).

The non-arbitrary nature of the Five Levels is created by determining the boundaries of each of the five levels using several statistical indicators of risk (e.g., absolute recidivism rates, percentiles, estimates of relative risk). These indicators should 
be derived from large representative samples of the population of interest and include sample sizes of at least 500 participants with 100 recidivists over a two-year time period (Hanson, Bourgon, et al., 2017). For example, if someone wanted to adopt the Five-Level system for an established actuarial tool designed to predict general offending, they would need to calculate the statistical indicators of risk using data that contained information on at least 500 individuals, at least 100 of which were determined to have recidivated with a general offence over a 2-year period. Information can also be combined from several datasets in order to meet the required parameters. Once the statistical indicators of risk are derived from the data, the authors of the Five-Levels provide guidance on how the indicators can be used to define the boundaries of each level. For example, Level I should include scale scores associated with recidivism estimates of 5\% or lower while the lower boundary of the highest risk level, Level V, would be associated with recidivism estimates of over $85 \%$. Level III should include the middle of risk distribution (based on percentiles). Level II then includes all scores between Level I and III, with a meaningfully lower risk than those in Level III. Level IV includes those meaningfully higher scores than Level III and lower than Level V (Hanson, Bourgon, et al., 2017). See Hanson, Babchishin et al. (2017) for a full example of how to populate each level. The levels are further highlighted in Table 2, with corresponding needs and strengths, the correctional response, and prognosis of each level. 


\section{Table 2}

Five-Level Risk and Needs System

\begin{tabular}{|c|c|c|c|}
\hline $\begin{array}{l}\text { Risk } \\
\text { Level }\end{array}$ & Needs/ Strengths & $\begin{array}{l}\text { Correctional } \\
\text { Response }\end{array}$ & Prognosis \\
\hline Level I & $\begin{array}{l}\text {-very few } \\
\text { criminogenic/non- } \\
\text { criminogenic needs } \\
\text {-clear strengths in all } \\
\text { three domains of risk }\end{array}$ & $\begin{array}{l}\text {-custody may worsen } \\
\text { recidivism outcomes }\end{array}$ & $\begin{array}{l}-1-2 \% \text { recidivism risk } \\
\text {-expected to desist from } \\
\text { criminal behaviour without } \\
\text { correctional intervention }\end{array}$ \\
\hline Level II & $\begin{array}{l}\text {-acute, identifiable } \\
\text { criminogenic needs } \\
\text {-some non- } \\
\text { criminogenic needs } \\
\text {-some identifiable } \\
\text { strengths }\end{array}$ & $\begin{array}{l}\text {-long term custody } \\
\text { counter productive } \\
\text {-community } \\
\text { supervision }\end{array}$ & $\begin{array}{l}\text {-two-year recidivism rate of } \\
19 \% \\
\text {-will transition to Level I and } \\
\text { desist from criminal } \\
\text { behaviour once needs have } \\
\text { been addressed }\end{array}$ \\
\hline Level III & $\begin{array}{l}\text {-multiple criminogenic } \\
\text { needs from all three } \\
\text { domains } \\
\text {-few strengths - needs } \\
\text { may be blocking } \\
\text { strengths }\end{array}$ & $\begin{array}{l}\text {-custody for the } \\
\text { purpose of short-term } \\
\text { risk management } \\
\text {-benefit from } \\
\text { community } \\
\text { supervision to target } \\
\text { needs }\end{array}$ & $\begin{array}{l}\text {-two-year recidivism rates of } \\
40 \% \\
\text {-significant reduction in } \\
\text { criminal behaviour with } \\
\text { evidence-based interventions } \\
\text {-may drop to Level II, though } \\
\text { could remain in justice } \\
\text { system for } 3-5 \text { years }\end{array}$ \\
\hline Level IV & $\begin{array}{l}\text {-many criminogenic } \\
\text { needs } \\
\text {-severe non- } \\
\text { criminogenic needs } \\
\text {-chronic barriers to } \\
\text { accessing strengths }\end{array}$ & $\begin{array}{l}\text {-custody } \\
\text {-intense community } \\
\text { supervision upon } \\
\text { release } \\
\text {-in custody and } \\
\text { community-based } \\
\text { intervention }\end{array}$ & $\begin{array}{l}\text {-two-year recidivism rates of } \\
65 \% \\
\text { - significant reduction in } \\
\text { criminal behaviour with } \\
\text { evidence-based interventions } \\
\text {-high recidivism rates will } \\
\text { decrease over time }\end{array}$ \\
\hline
\end{tabular}

\begin{tabular}{llll}
\hline Level V & -severe criminogenic & -custody with highly & $-85-90 \%$ recidivism rates \\
and non-criminogenic & structured, & -reductions in recidivism may \\
needs & comprehensive, & take place gradually over \\
& & & decades
\end{tabular}




\begin{tabular}{lll}
\hline -limited, if any, & -step-down release \\
resources and strengths & $\begin{array}{l}\text {-reductions may be possible } \\
\text { changes }\end{array}$ & $\begin{array}{l}\text { with intensive evidence-based } \\
\text { interventions }\end{array}$ \\
& $\begin{array}{l}\text {-intense supervision } \\
\text { upon release }\end{array}$ & \\
&
\end{tabular}

Currently the Five-Level system has been applied to some of the most widely used actuarial scales for the assessment of sexual recidivism such as the STATIC tools (Static-99R; Static-2002R, see Hanson, Babchishin et al., 2017) and the Violence Risk Scale-Sexual Offense Version (VRS-SO; Wong et al., 2003-2017, see Olver et al., 2018). When applying the framework to samples of individuals who committed sexual offences, it is rare that recidivism rates exceed 50\%, thus Hanson and colleagues (2017) named the fourth and fifth levels for the STATIC tools, Level IVa and Level IVb, respectively. The same results were found when Olver and colleagues (2018) adopted the framework for the VRS-SO.

Prior to adopting the Five-Levels, the STATIC tools had a concordance rate of $51 \%$, meaning that only $51 \%$ of individuals received the same risk category label in both the Static-99R and the Static-2002R (Hanson, Babchishin, et al., 2017). However, with the new Five-Levels, concordance between the two instruments increased to $72 \%$ (Hanson, Babchishin, et al., 2017). Interclass correlations were also significantly higher for the Five-Level risk categories than the original risk categories (.84 vs. .73). The main benefit from adapting the Five-Levels for the STATIC tools is that the same inferences can be made about individuals who commit sexual offences in the same risk category regardless of which measure is chosen (Hanson, Babchishin, et al., 2017). As the FiveLevels were adopted for the VRS-SO as well, the same inferences can be made regarding 
individuals who commit sexual offences in each risk category. Further benefits can be seen from adopting the Five-Levels for the VRS-SO (Olver et al., 2018); as the VRS-SO is a dynamic risk tool, the Five-Levels were populated for the static score, the dynamic score, and the total score. The authors also took into consideration the change scores, as a client moves through treatment and thereby reducing their VRS-SO score, their category on the Five-Levels can also change (Olver et al., 2018).

More recently, the Five-Level system has been adopted to a general recidivism assessment, the Level of Service Inventory- Revised (LSI-R; Andrews \& Bonta, 2001, see Kroner et al., 2019). Using two datasets of probationers and community parolees, the authors were able to demonstrate a stronger relationship between probabilities of reoffending and the observed base rates for each of the Five-Levels than with the original LSI-R categories (Kroner et al., 2019). However, the lower risk sample of probationers was found to more heavily populate the lower risk levels, and the opposite was true of the parolee sample. Neither sample populated the fifth level, leading to the distinction of Level IVa and IVb (Kroner et al., 2019), similar to Hanson, Babchishin et al. (2017).

\section{The Five-Level System and Risk Decisions}

Although the Five-Level system may provide the potential for differences in risk decision-making, this needs to be tested. In an unpublished study, Helmus and colleagues (2018) examined whether information presented in the format of the Five-Levels could produce better risk decisions for an individual who committed a sexual offence than the status quo risk communication from the Offender Risk Assessment Guide (ORAG). Using a sample of 484 laypeople, recruited from Mechanical Turk, an online survey company, the researchers utilized a 2 × 2 design, manipulating risk level (high vs. low) 
and communication format (status quo vs. Five-Levels). Laypeople's interpretation of risk was strongly predicted by their preconceived attitudes (e.g., $61 \%$ of the sample indicated that they thought all individuals who committed sexual offences were high risk). When asked for a dichotomous prediction of whether the individual would commit a new sexual offence within five years, $67 \%$ said yes. Overall there was a main effect of risk level where participants were able to distinguish between low and high risk on dichotomous and continuous measures of risk perception. However, there was no main effect of communication format; the Five-Levels did not have an effect on any of the relevant outcomes.

\section{The Current Study}

The Five-Level system encompasses all the guidelines recommended for proper risk communication: numerical estimations of individual risk level, identification of relevant risk factors, identification of risk management strategies and treatment options, and presented in an appropriate way to the decision maker (Conroy \& Murrie, 2007). Previously, there has been no consensus about the definition of categorical risk levels, and no consensus about the probabilities of offending that coincide with these categories. With the adoption of the Five-Level system, decision makers and clinicians can be confident in knowing what the risk categories mean, regardless of which risk instrument is chosen. This can have numerous benefits including further advancing adherence to the RNR model. As the risk principle suggests that the intensity of an intervention should match the individual's risk level, with the adoption of the Five-Levels, it could be easier to differentiate the amount of treatment necessary for individuals in the differing levels 
This in turn could save costs to the CJS and facilitate public safety (Hanson, Bourgon, et al., 2017).

Despite the proposed benefits of communicating risk using the Five-Levels, research is needed to validate the effectiveness of the Five-Level system and to ensure individuals can understand and implement the information accordingly. The objective of the current study was to assess whether utilizing the Five-Level Risk and Needs System resulted in different risk-relevant decisions compared to the standard risk communication format among a sample of laypersons. The current study was a 3 x 2 between-subjects design, varying risk level (low, moderate, high) and communication format (status quo vs. Five-Levels) in a mock risk assessment for a parole decision making case. The outcomes of interest related to perceptions of risk (e.g., granting parole, perceptions of absolute and relative risk of recidivism, etc.), treatment amenability and management (e.g., likelihood that the individual would benefit from treatment, follow parole conditions), and overall understandability and importance of the information presented in the report. Unlike previous research (i.e., Helmus et al., 2018), the current study manipulated the variables within a fuller risk assessment report as opposed to relying on short vignettes. Based on previous risk communication research, several hypotheses were proposed.

\section{Risk Hypotheses}

1) A main effect of risk level was expected, such that participants assigned to the higher risk conditions would be less likely to grant Mr. Wilson parole, compared to those in the lower risk condition. It was also expected that, as there was a progression of risk level assigned (low, moderate, high), participants would 
prescribe more punitive decisions to Mr. Wilson (i.e., more likely to reoffend in the next two years, higher probability of reoffence, less comfortable if released).

2) No main effects of communication format were expected (consistent with Helmus et al., 2018) on risk-relevant decisions.

3) A significant interaction was expected between risk level and communication format, such that for those in the moderate risk condition, the Five-Level group would make lower risk decisions, while the status-quo group would make higher risk decisions. This was hypothesized due to the variation around moderate risk. While Helmus and colleagues (2018) only had low and high risk conditions, having a moderate risk condition allows for more fluctuations and other information to be considered (e.g., treatment information, overall opinion of risk) when making a decision. Since the Five-Levels condition offers more information on treatment amenability and management, it was hypothesized that those in this condition would consider other information and make lower risk decisions than those in the status quo condition.

\section{Treatment/Management Relevant Hypotheses}

4) There would be a main effect of risk level on treatment outcomes, such that those in the lower risk conditions would rate the individual more favourably on treatment and management outcomes compared to those in the higher risk conditions.

5) There would be a main effect of communication format on treatment/management outcomes; those in the Five-Level condition should make more decisions that would suggest the individual will be more likely to desist from crime and be 
amenable to treatment due to having more information regarding treatment outcomes and amenability.

6) A significant interaction would be expected, such that for those in the moderate risk condition, the Five-Level group would make more positive treatment decisions, while the status-quo group would make lower. This is due to the FiveLevels giving more information about treatment and the possibility of rehabilitation than the status quo condition.

\section{Understandability/Importance Hypotheses}

7) No main effect of risk level on understandability/importance was expected, as all risk levels are provided with the same amount of information in the assessments.

8) There would be a main effect of communication format on understandability/importance, such that those in the Five-Levels condition would find the information more understandable/important and feel that they had been provided enough information to make a decision regarding parole and risk. 


\section{Method}

\section{Participants}

Power analysis was conducted with $\mathrm{G}^{*}$ Power to decide an appropriate sample size for each group of participants for a $3 \times 2$ design. With an expected small to moderate effect size of $f=.20$ for $80 \%$ power, 210 participants were recommended, with 35 in each cell (Faul et al., 2007). Participants included 252 community members, recruited through snowball sampling on various social media platforms, including Facebook, Twitter, Reddit, and Kijiji. Five participants were removed for not answering more than half of the questions, and nine were removed for failing validity checks leaving a total sample of 238 participants.

Participants included 182 (76.5\%) women, 54 (22.7\%) men, one participant who identified as non-binary, and one who preferred not to say $(0.8 \%)$. Participants ranged in age from 18 to $72(M=37.3, S D=13.7)$. The sample included 209 Caucasian participants (87.8\%), followed by 9 Asian participants (3.8\%), 5 Hispanic/Latinx participants (2.1\%), 3 Indigenous participants (1.3\%), 3 Middle Eastern participants $(1.3 \%)$, and 2 Black participants $(0.8 \%)$. The majority of the sample had a bachelor's degree $(n=90,37.8 \%)$ or a college degree $(n=55,23.1 \%)$, followed by a Master's degree $(n=39,16.4 \%)$, secondary school $(n=31,13 \%)$, and professional/doctoral degree $(n=23,9.7 \%)$. Thirty-eight $(16 \%)$ participants had a background in law and legal studies, while 88 (37\%) had a background in psychology. Seventy-four participants $(31.1 \%)$ indicated that they use risk assessments in their professional life.

\section{Measures}

Risk Assessment Reports 
Six mock risk assessment reports were created to closely resemble real risk assessment reports (see Blais \& Forth, 2014). The case being assessed was that of Darrell Wilson, a mock individual convicted of a violent offence. Mr. Wilson was described as being 43 years old and serving a two-and-a-half-year sentence for assault and robbery. The report included sections on each of the following: his current offence, psychosocial development, criminal history, mental health history and psychiatric diagnosis, correctional and rehabilitation history, the risk assessments used, and treatment and management. In order to make the assessments as accurate as possible, these sections were included as past research has shown that more than $70 \%$ of real risk assessments include these sections (Blais \& Forth, 2014). Within the risk assessment portion, there was information on three assessment scales, as this was the average number of scales used to assess risk in a single assessment, as found in Blais and Forth (2014). The length of the risk assessment reports also approximated the length of the risk assessment portion of real reports as much as possible while balancing the total length of the study. In Blais and Forth (2014) the average length of the risk assessment portion was approximately four pages. The mock reports for the current study were 3.5 pages long. Having a more realistic length is also a strength of the current study over past studies that have utilized short vignettes consisting of single paragraphs (e.g., Helmus et al., 2018). The full reports are provided in Appendix B.

Information Consistent across all Mock Assessments. Across all mock assessments, Mr. Wilson was described as the second eldest of three children, raised by his mother and grandmother, with minor behavioural issues growing up. He was described as completing high school equivalency and as having employment that he can 
return to upon release, though has never been able to have a long-term romantic partner. Mr. Wilson was described as meeting the criteria for a substance use disorder. In terms of the risk assessment, each condition presented information from the LSI-R (Andrews \& Bonta, 1995), the Statistical Information for Recidivism Scale (SIR; Nuffield, 1982), and the HCR-20 (Webster et al., 1997). Each condition presented an overall opinion of risk at the end of the mock assessment.

Information that Varied across Mock Assessments. The first variable manipulated was Mr. Wilson's level of risk. Risk level was manipulated by changing the scores on the LSI-R, the SIR ${ }^{1}$, and the items endorsed on the HCR-20. In order to realistically portray an individual as having a low, moderate, or high risk of reoffending, it was necessary to change not only the risk assessment information, but some of the other case details as well. For example, it did not make sense to have a low risk individual with the same criminal history or treatment prognosis as a high risk individual. Appendix E outlines the ways in which the case details differ as a function of risk level and communication format.

The second variable manipulated was how the risk information was communicated: status quo vs. Five-Levels. Importantly, the status quo cases were based on how risk is typically communicated as indicated by clinician surveys (i.e., Viljoen et al., 2010) and a coding of actual assessment reports (Blais \& Forth, 2014). The FiveLevel conditions varied how the risk information from the actuarial scales was presented

\footnotetext{
${ }^{1}$ An error occurred in writing the SIR scale scores for the low risk condition. The low risk status quo SIR categorical rating was Level 2/5, while for the Five-Levels it was Level 1/5. A t-test was run to examine whether there were significant differences between the low risk conditions on likelihood to reoffend scores $(0-100 \%)$ with no effects being found, $t(69)=0.678, p=0.50,95 \%$ CI $[-7.56,15.34]$. Both levels provided "good" reintegration potential and the same recidivism risk scores (see Appendix E for a full breakdown).
} 
consistent with the level descriptions in Hanson, Bourgon et al. (2017). Given that the Five-Levels aims to increase concordance in the information presented from several scales, an integrated summary of Mr. Wilson's risk, based on the assigned risk level was also provided. The Five-Levels descriptions were adapted from example risk communication excerpts provided for the Static-99R and in the Five-Levels manual (Hanson, Bourgon, et al., 2017). The Five-Levels condition presented a risk level, risk factors, a recidivism estimate over two years (including a range), and risk management and intervention information along with the overall prognosis. Meanwhile, the status quo condition presented the LSI-R findings in accordance with the original author's intentions (i.e., the LSI-R scores vary from 0-54 and scores align with five risk categories ranging from low to high). The SIR scale findings were also presented in a similar fashion with total scores provided with a corresponding risk category. For the SIR scale, lower scores indicate good reintegration potential, or a lower risk of recidivism, while higher scores indicate a poor reintegration potential, or a higher risk of recidivism.

The high risk condition for Mr. Wilson was defined as a score of 41 on the LSI-R (which placed him in the high LSI-R risk category), a 7 on the SIR (which placed him in the fair/poor reintegration potential category), with four risk factors and three protective factors listed from the HCR-20. The Five-Level high risk condition placed Mr. Wilson in Level IV of V and described reoffending rates $(\sim 65 \%)$, treatment management, and intended outcomes. In the moderate risk condition, Mr. Wilson was given an LSI-R score of 25 (moderate risk condition), with a score of 2 on the SIR (fair reintegration potential risk condition), and three risk factors and three protective factors listed from the HCR-20. In the corresponding Five-Levels condition he was placed in Level III of V (the average 
risk level). The low risk condition saw Mr. Wilson with an LSI-R score of 7 (low risk level), a SIR score of -4 (good reintegration potential category), with two risk factors and three protective factors listed from the HCR-20. In the corresponding Five-Levels condition, he was placed in Level II of V.

\section{Demographic Questionnaire}

Participants were asked several demographic questions, including their age, gender, race, and educational background. Participants were also asked whether they had a law or psychology background, or experience with risk assessment in their daily life (see Appendix C).

\section{Outcome variables}

Risk Relevant Outcomes (Appendix C). Upon completion of reading the mock risk assessment, participants were asked if they would grant Mr. Wilson parole (yes/no) and to rate their confidence in their decision (0-100\%). Participants were then asked to choose an ordinal risk ranking for Mr. Wilson (low, low-moderate, moderate, moderatehigh, high). As the risk assessment explicitly stated a risk level, I wanted to see how consistent participants' answers would be with the risk level they were presented with. As such, this variable was recoded. Participants assigned to the low risk condition who subsequently rated Mr. Wilson as "low" or "low-moderate" risk were recoded into “consistent risk assignment (1)", while any other answer was coded as "inconsistent risk assignment (0)". This was repeated for the moderate and high risk conditions (high encompassed "moderate-high" and "high") such that one variable was made encompassing consistent risk prediction (1) or not (0). 
Next participants were asked whether Mr. Wilson was more likely, less likely or about as likely to commit a new crime compared to the average offender. Similar to the categorical ratings, the relative ratings were recoded into consistency ratings. Those in the low risk condition who chose "less likely" were coded as consistent, those in moderate risk condition who chose "about the same", and those in high risk condition who chose "more likely" were similarly coded as consistent. All other responses were coded as inconsistent. In terms of absolute recidivism risk, participants were then asked a dichotomous question of whether or not Mr. Wilson would commit a new offence in the next two years (yes/no). They were subsequently asked what they believed the likelihood from $0-100 \%$ that he would commit a new crime within two years. They were also asked from $0-100 \%$ how comfortable they would be if Mr. Wilson was released.

Treatment/Management Outcomes. Participants also completed five questions about treatment and management using a five-point Likert scale $(1=$ very unlikely, $5=$ very likely): how likely he is to comply with conditions, how likely he is to benefit from rehabilitation/treatment, how likely is he to lower his risk of reoffending in the next five years, how likely is he to stay crime free over the next five years, how likely is it that he would desist from crime completely.

Understandability/Importance Outcomes. Finally, participants were asked how understandable they found the information provided to them in the risk assessment on a five-point Likert scale from 1 = very difficult to understand to $5=$ very easy to understand. The responses were then dichotomized into either having understandability issues (1-4) or having no understandability issues (5). Two dichotomous questions were also included: whether they had enough information to determine Mr. Wilson's risk to 
reoffend (yes/no), and enough information to determine his parole decision (yes/no). Participants were also asked to rate the importance of 11 factors in making their decisions on a five-point Likert scale $(1=$ not important, 5 = very important $)$ : severity of the offence, level of victim injury, criminal history, treatment history, strength and risk factors, the overall risk assessment, information from the LSI-R, the SIR, the HRC-20, and the overall opinion provided at the end of the assessment. Finally, participants were asked if there was any other information that could have been provided to make their decisions about Mr. Wilson easier.

\section{Procedure}

The study received ethics approval from the Carleton University Research Ethics Board-B (Clearance \#: 112785). Participants were recruited online through the use of snowball sampling (Appendix D), with the incentive for completing the study being entered to win a \$100 Amazon gift card. The survey link was posted and shared on Facebook, Twitter, Reddit, and Kijiji. The survey link took participants to the informed consent page (Appendix A), and, if they consented, they were brought to the eligibility questions. If they did not consent, they were taken to the end of the survey. Eligibility requirements included being 18 years of age or older and being able to read and write in English. After this, participants were randomly and equally assigned to one of six conditions (Appendix B). Upon starting the study, participants were permitted to take 2 weeks to complete it, after which time the study was closed at the last saved answer. Two validity check questions were included: what crime was Mr. Wilson most recently charged with, and what psychiatric disorder was Mr. Wilson diagnosed with? Participants were excluded for failing both questions $(n=5)$. Half-way through the survey a third 
manipulation question was included stating: This question is meant to ensure that the survey software is working correctly. Please answer 3 (1 to 5 answer choices). Four participants were excluded for failing to select 3. Median time to complete the survey was 13 minutes.

\section{Results}

\section{Preliminary Analyses}

\section{Assumptions}

Prior to conducting any analyses, the data was examined for major assumptions including missing data, outliers, and normality. Listwise deletion was used for participants with missing data, as the number of missing values was less than 15 , and as such they were excluded from the given analyses. Outliers were examined for each analysis and determined based on a $Z$-score of $\geq|3.29|$ (Tabachnick \& Fidell, 2013). Very few outliers were found (no more than 3 per analyses) and they were examined for mistakes or errors, such as data entry errors and time to completion, and none were found; therefore, outliers were kept in the data ${ }^{2}$, as these data represent real responses and there has been evidence that suggests leaving outliers in the data does not correspond to more errors or weaker evidence against the null hypothesis in psychological research (Bakker \& Wicherts, 2014). Assumptions for ANOVA were examined, including normality (Shapiro-Wilk test) and equal variance (Levene's test). Assumptions for binomial logistic regressions were also examined, including linearity (which is assumed with dummy coded variables), multicollinearity (assumed as there is only 1 predictor),

\footnotetext{
${ }^{2}$ Analyses were run with and without outliers and no significant differences were found. Therefore, outliers were left in the dataset.
} 
and goodness of fit (Homer and Lemeshow test; Homer \& Lemeshow, 1989). All assumptions were met for each analysis.

\section{Equivalence Tests}

In order to ensure random assignment was successful, equivalence tests were run on each of the demographic variables. Chi-square analyses revealed no significant effects of gender (risk level: $\chi^{2}[6]=4.18, p=.65$, communication format: $\chi^{2}[3]=2.94, p=.40$ ), race (risk level: $\chi^{2}[16]=9.74, p=.88$, communication format: $\chi^{2}[8]=5.97, p=.65$ ), education (risk level: $\chi^{2}[8]=11.43, p=.18$, communication format: $\chi^{2}[4]=3.25, p=$ .52 ), law background (risk level: $\chi^{2}[2]=1.04, p=.60$, communication format: $\chi^{2}[1]=$ $1.42, p=.23$ ), psychology background (risk level: $\chi^{2}[4]=4.23, p=.38$, communication

format: $\chi^{2}[2]=4.19, p=.12$ ), or the use of risk assessment in professional life (risk level: $\chi^{2}[4]=7.09, p=.13$, communication format: $\left.\chi^{2}[2]=1.23, p=.54\right)$. A one-way ANOVA revealed no significant effects of age on risk level $(F[2,233]=0.92, p=.40)$, while a ttest revealed no significant effects of age on communication format $(t[234]=-1.15, p=$ .25). As such, all groups appeared equivalent on all demographic questions.

\section{Principle Component Analysis}

There was a high degree of similarity across the five Likert-style questions pertaining to treatment/management (e.g. "how likely is Mr. Wilson to benefit from rehabilitation/treatment?", "how likely is Mr. Wilson to lower his risk of reoffending over the next five years?"), with Pearson correlations between the five outcomes ranging from .19 to .76 (see Table 4). As such, a principle component analysis with varimax rotation was run to examine factor loadings of the five outcomes. A one-factor solution accounting for $61 \%$ of the variance was chosen. This was done by examining the 
interpretability criterion (outlined on Laerd Statistics, 2015), examining the factor loadings, and the eigenvalues (one factor eigenvalue $=3.05$, two factor $=0.88$; Kaiser, 1960). A forced factor rotation was then done with one factor, to ensure the solution was accurate. A composite variable was created by summing the individual scores on each item, with higher scores indicative of more positive attitudes toward treatment amenability and management. Reliability for the new scale was $\alpha=.83$. Table 4 presents the factor loadings.

\section{Table 3}

Correlations of Treatment/Management Variables

\begin{tabular}{llllll}
\hline & 1 & 2 & 3 & 4 & 5 \\
\hline 1 Comply with parole conditions & - & & & & \\
2 Benefit from treatment & $\mathbf{. 3 9 8}$ & - & & & \\
3 Lower risk of reoffending over 2 years & $\mathbf{. 5 3 2}$ & $\mathbf{. 4 7 1}$ & - & & \\
4 Stay crime free for 5 years & $\mathbf{. 6 0 5}$ & $\mathbf{. 3 3 6}$ & $\mathbf{. 6 3 4}$ & - & \\
5 Desist from crime completely & $\mathbf{. 5 1 8}$ & $\mathbf{. 1 9 1}$ & $\mathbf{. 5 5 9}$ & $\mathbf{. 7 6 4}$ & - \\
\hline
\end{tabular}

Note. Bolded values are significant at $p<.01$.

\section{Table 4}

Rotated Factor Loadings of Treatment/Management Variables

\begin{tabular}{ll} 
& Factor Loadings \\
\cline { 2 - 2 } Item & 1 \\
\hline Stay crime free for 5 years & $\mathbf{. 8 8 1}$ \\
Lower risk of reoffending over 2 years & $\mathbf{. 8 2 7}$ \\
Desist from crime completely & $\mathbf{. 8 0 6}$ \\
Comply with parole conditions & $\mathbf{. 7 8 8}$ \\
Benefit from treatment & $\mathbf{. 5 6 3}$ \\
\hline
\end{tabular}

Note. Bolded values denote factor loadings.

Similarly, for the 11 outcomes utilized to assess how important certain information was in making decisions $(1=$ not important to $5=$ very important $)$, there was a high degree of similarity across the 11 questions. Pearson correlations between the 11 outcomes ranged from .07 to .89 , with the majority being over .30 (see Table 5). A second principle component analysis with varimax rotation was run to see the factor 
loadings of the 11 variables. One item did not load onto any factor ("risk factors listed [e.g., substance use]") and was therefore not included. This was determined using Hair and colleagues (1998) factor loading cut-offs for defined samples sizes (for a sample size of 238 factor-loading cut-offs should be between .35-.40). A three-factor solution was chosen accounting for $70 \%$ of the variance, by examining the factor loadings and the eigenvalues (three factor eigenvalue $=1.48$, four factor $=0.68 ;$ Kaiser, 1960). A forced factor rotation was then done with three factors, to ensure the solution was accurate. The three new variables were created by summing the individuals scores on each item into a total score. The item breakdown in presented in Table 6. The first new variable was labeled Crime Severity/Criminal History, composing three items relating to severity of the crime, victim injury, and criminal history information $(\alpha=.74)$. The second variable was labeled Treatment/Opinion, and composed of three variables related to treatment history, strengths, and the overall opinion on the risk assessment $(\alpha=.70)$. The third variable was labeled Risk Assessment Information and comprised of four items related to the overall risk assessment, and information from the LSI-R, SIR, and HCR-20 $(\alpha=.91)$.

\section{Table 5}

Correlations of Decision Making Importance Variables

\begin{tabular}{|c|c|c|c|c|c|c|c|c|c|}
\hline & 1 & 2 & 3 & 4 & 5 & 6 & 7 & 8 & 9 \\
\hline $\begin{array}{l}1 \text { Severity of the current } \\
\text { offence }\end{array}$ & - & & & & & & & & \\
\hline 2 Level of victim injury & .631 & - & & & & & & & \\
\hline 3 Criminal history & .442 & .373 & - & & & & & & \\
\hline 4 Treatment history & .105 & .071 & .341 & - & & & & & \\
\hline 5 Strength factors listed & .073 & .078 & .177 & .578 & - & & & & \\
\hline 6 Risk factors listed & .254 & .186 & .311 & .389 & .303 & - & & & \\
\hline $\begin{array}{l}7 \text { Risk assessment } \\
\text { overall }\end{array}$ & .212 & .267 & .279 & .373 & .253 & .489 & - & & \\
\hline 8 LSI-R & .184 & .192 & .213 & .221 & .121 & .373 & .580 & - & \\
\hline 9 SIR & $.165^{*}$ & $.154^{*}$ & .216 & .217 & .199 & .321 & .517 & .863 & - \\
\hline 10 HCR-20 & .170 & .187 & .176 & .239 & .208 & .355 & .567 & .898 & .809 \\
\hline
\end{tabular}


11 Overall opinion 087 109

\section{2}

453

282

$.342 \quad .508$

.457

Note. Bolded values are significant at $p<.01 .{ }^{*}$ denotes significance at $p<.05$.

\section{Table 6}

Rotated Factor Loadings for Decision Making Importance Variables

\begin{tabular}{llll}
\hline & \multicolumn{3}{c}{ Factor Loadings } \\
\cline { 2 - 4 } Items & 1 & 2 & 3 \\
\hline Composite 1: Severity of crime/criminal & & & \\
history & & & .053 \\
$\quad$ Severity of the current offence & $\mathbf{. 8 7 4}$ & .016 & .096 \\
$\quad$ Level of victim injury & $\mathbf{. 8 3 3}$ & -.023 & .111 \\
$\quad$ Criminal history & $\mathbf{. 6 5 1}$ & .310 & \\
Composite 2: Treatment/opinion & & & .135 \\
$\quad$ Treatment history & .100 & $\mathbf{. 8 6 0}$ & .029 \\
$\quad$ Strength factors listed & .014 & $\mathbf{. 8 2 7}$ & .496 \\
Overall opinion & .019 & $\mathbf{. 5 2 5}$ & \\
Composite 3: Risk assessment info & & & $\mathbf{. 6 3 1}$ \\
Risk assessment overall & .224 & .385 & $\mathbf{. 9 5 5}$ \\
LSI-R & .084 & .080 & $\mathbf{. 9 1 7}$ \\
SIR & .088 & .080 & $\mathbf{. 9 2 2}$ \\
HCR-20 & .059 & .130 &
\end{tabular}

Note. Bolded values denote factor loadings.

\section{Descriptive Information}

Table 7 presents participants' responses collapsed across conditions. Overall, the majority of the sample (76.8\%) said they would grant Mr. Wilson parole and were fairly confident in their decision $(M=74.45 \%)$. Almost half the sample had no issues understanding the information presented in the risk assessment (48.3\%). There was also high overall importance placed on the three composite variables regarding criminal history, treatment, and risk assessment information. 


\section{Table 7}

Participant Responses on all Outcomes

\begin{tabular}{|c|c|c|c|}
\hline Categorical variables & $N$ & $\mathrm{n}(\%)$ & \\
\hline \multicolumn{4}{|l|}{ Risk outcomes } \\
\hline Parole decision & 237 & & \\
\hline Yes & & $182(76.8 \%)$ & \\
\hline Categorical level of risk & 237 & & \\
\hline Low & & $34(14.3 \%)$ & \\
\hline Low-moderate & & $55(23.1 \%)$ & \\
\hline Moderate & & $78(32.8 \%)$ & \\
\hline Moderate high & & $58(24.4 \%)$ & \\
\hline High & & $12(5 \%)$ & \\
\hline \multicolumn{4}{|l|}{ Relative risk } \\
\hline Less likely & & $87(36.6 \%)$ & \\
\hline More likely & & $71(29.8 \%)$ & \\
\hline About the same & & $80(33.6 \%)$ & \\
\hline Dichotomous risk & 236 & & \\
\hline Yes & & $97(40.8 \%)$ & \\
\hline \multicolumn{4}{|l|}{ Understandability outcomes } \\
\hline Ease of understanding* & 237 & & \\
\hline No issues & & $115(48.3 \%)$ & \\
\hline \multicolumn{4}{|l|}{ Enough info for recidivism } \\
\hline Yes & & $186(78.2 \%)$ & \\
\hline \multicolumn{4}{|l|}{ Enough info for parole } \\
\hline Yes & & $176(73.9 \%)$ & \\
\hline Continuous variables & $N$ & $M(S D)$ & Range \\
\hline \multicolumn{4}{|l|}{ Risk outcomes } \\
\hline Confidence in parole decision & 236 & $74.45(17.36)$ & $11-100$ \\
\hline Likelihood of new crime & 237 & $45.01(22.90)$ & $2-100$ \\
\hline Comfortability if released & 233 & $51.89(27.24)$ & $0-100$ \\
\hline \multicolumn{4}{|c|}{ Treatment/management outcomes } \\
\hline Treatment amenability* & 237 & $16.38(3.90)$ & $7-25$ \\
\hline \multicolumn{4}{|c|}{ Understandability/importance outcomes } \\
\hline Criminal history* & & $12.23(2.22)$ & $4-15$ \\
\hline Treatment* & & $12.42(2.09)$ & $3-15$ \\
\hline Risk assessment* & & $15.74(3.24)$ & $4-20$ \\
\hline
\end{tabular}

Note. $N=238$, unless otherwise stated. ${ }^{*}$ denotes recoded/composite variables. 


\section{Risk Relevant Hypotheses (H1, H2, and H3)}

\section{Parole Decision and Confidence}

Overall, it was hypothesized that there would be main effects of risk level on risk relevant outcomes $(\mathrm{H} 1)$, no main effects of risk communication format $(\mathrm{H} 2)$, and a significant interaction between risk level and risk communication format $(\mathrm{H} 3$; refer to $\mathrm{p}$. 26 for further justification for each hypothesis). The first risk-relevant outcome examined was the parole decision. In order to test the hypotheses that assigned risk level and risk communication format would be related to parole decisions, a binary logistic regression was conducted with risk level (low, moderate, high) and communication format (status quo, 5-Levels) entered into the model simultaneously and parole decision (yes vs. no) entered as the outcome. For risk level, low risk was set as the reference category and for communication format, status quo was selected as the reference category (results appear in Table 8). The overall model was significant, $\chi^{2}(5, N=237)=23.15, p<.001$. Consistent with $\mathrm{H} 1$, results indicated a significant main effect of risk level such that those in the moderate risk condition were significantly less likely to grant parole than those in the low risk condition, Wald $\chi^{2}(1)=6.06, p=.014$. Additionally, participants in the high risk condition were significantly less likely to grant parole than those in the low risk condition, Wald $\chi^{2}(1)=8.83, p=.003$. Consistent with $\mathrm{H} 2$, there was no significant main effect of communication format, Wald $\chi^{2}(1)=2.82, p=.093$. Finally, consistent with H3, there was also a significant interaction, Wald $\chi^{2}(1)=3.91, p=.048$, suggesting that those in the Five-Level condition (compared to the status quo condition) were significantly more likely to grant parole if they were in the moderate risk condition compared to those in the low risk condition. The interaction is plotted in Figure 1. 


\section{Table 8}

Logistic Regression for Parole Decision

\begin{tabular}{|c|c|c|c|c|c|}
\hline & $\mathrm{R}^{2}$ & $\mathrm{~B}(\mathrm{SE})$ & $p$ & OR & CI $(95 \%)$ \\
\hline Model & $.141 * *$ & & & & \\
\hline 5-Levels (vs. status quo) & & $-1.89(1.12)$ & .093 & 0.15 & $0.02,1.37$ \\
\hline Moderate (vs. low) & & $-2.64(1.07)$ & .011 & 0.07 & $0.01,0.58$ \\
\hline High (vs. low) & & $-3.15(1.06)$ & .003 & 0.04 & $0.01,0.34$ \\
\hline 5-L * Mod Risk & & $2.47(1.25)$ & .048 & 11.82 & $1.02,136.78$ \\
\hline 5-L * High Risk & & $2.12(1.21)$ & .080 & 8.32 & $0.78,89.26$ \\
\hline
\end{tabular}

Note. ${ }^{* *}$ denotes significance at $p<.01$.

\section{Figure 1}

Interaction Plot of Granted Parole Decisions by Randomly Assigned Risk Level (Low, Moderate, High) and Separated by Communication Condition (Status Quo vs. FiveLevels)

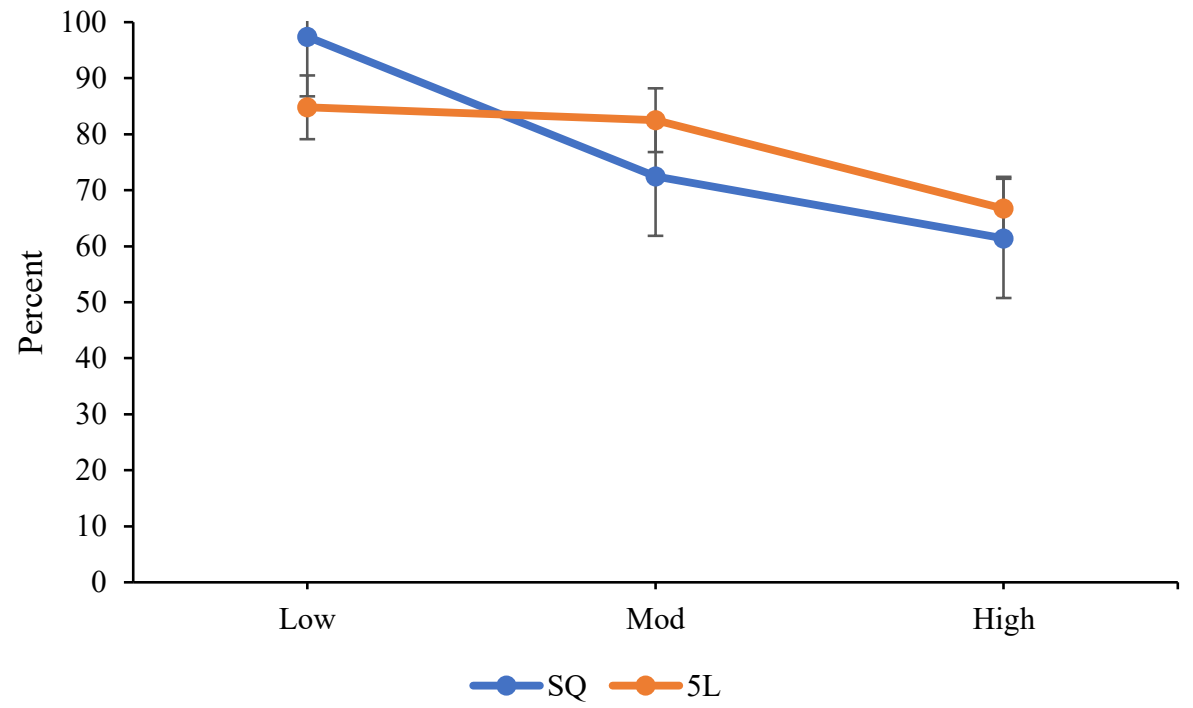

Note. $\mathrm{SQ}=$ Status quo, 5L = Five-Levels. Error bars represent standard errors.

A two-way random-effects ANOVA was used to analyze the effect of risk level (low, moderate, high) and communication format (status quo, 5-Levels) on confidence 
ratings in parole decisions $(0-100 \%)$. Consistent with $\mathrm{H} 1$, there was a significant main effect of risk, $F(2,230)=15.89, p<.001$, partial $\eta^{2}=.12$. Similarly and consistently with $\mathrm{H} 2$, there was no significant effect of communication $F(1,230)=0.86, p=.354$, partial $\eta^{2}=.004$, nor was the interaction significant, $F(2,230)=2.78, p=.06$, partial $\eta^{2}=.024$. To follow up the significant effect of risk, Tukey's HSD was utilized. The low risk condition $(M=82.24, S D=14.47)$ was the most confident in their decisions, and significantly differed from the moderate $(M=74.72, S D=17.49, p=.014, d=0.47,95 \%$ CI $[0.50,1.17])$ and high risk conditions $(M=67.78, S D=16.86, p<.001, d=0.91,95 \%$ CI $[0.58,1.24])$. The moderate risk condition was next confident and significantly differed from the high risk condition $(p=.018, d=0.40,95 \%$ CI $[0.09,0.71])$. Those in the high risk condition were the least confident in their decisions.

\section{Absolute Recidivism Risk and Likelihood of Recidivism}

In order to determine if there were differences in the dichotomous risk question (Will Mr. Wilson commit a new offence within two years? Yes vs. no), a logistic regression was utilized to examine the effects of risk level (low [reference category], moderate, high) and communication format (status quo [reference category], Five-Levels; see Table 9). The overall model was significant, $\chi^{2}(5, N=236)=46.55, p<.001$. Consistent with $\mathrm{H} 1$, there was a significant effect of risk, such that those in the moderate risk condition were more likely than those in the low risk condition to say Mr. Wilson would commit a new offence, Wald $\chi^{2}(1)=7.19, p=.007$. Similarly, those in the high risk condition were more likely than those in the low risk condition to say Mr. Wilson would commit a new offence, Wald $\chi^{2}(1)=19.30, p<.001$. Consistent with H2, there was no main effect of risk communication format on perceptions of absolute recidivism 
risk, Wald $\chi^{2}(1)=1.49, p=.223$. Contrary to $\mathrm{H} 3$, and contrary to the results on parole decision making, there was no significant interaction between risk level and communication format, Wald $\chi^{2}(1)=1.42, p=.491$.

\section{Table 9}

Logistic Regression for Dichotomous Risk Decisions

\begin{tabular}{|c|c|c|c|c|c|}
\hline ( & $\mathrm{R}^{2}$ & $\mathrm{~B}(\mathrm{SE})$ & $p$ & OR & CI $(95 \%)$ \\
\hline Model & $.24 * *$ & & & & \\
\hline 5-Levels (vs. status quo) & & $0.83(0.68)$ & .223 & 2.29 & $0.61,8.66$ \\
\hline Moderate (vs. low) & & $1.67(0.62)$ & .007 & 5.31 & $1.57,18.00$ \\
\hline High (vs. low) & & $2.70(0.62)$ & .000 & 14.88 & $4.46,49.61$ \\
\hline 5-L * Mod Risk & & $-0.98(0.82)$ & .236 & 0.38 & $0.08,1.89$ \\
\hline 5-L * High Risk & & $-0.59(0.82)$ & .475 & 0.56 & $0.11,2.77$ \\
\hline
\end{tabular}

Note. $* *$ denotes significance at $p<.01$.

Next, participants were asked to provide a likelihood (0-100\%) that Mr. Wilson would commit a new offence within two years (0-100\%). A two-way random-effects ANOVA was utilized to examine the effect of risk level (low, moderate, high) and communication format (status quo, 5-Levels) on this outcome. Again, consistent with H1, there was a significant main effect of risk, $F(2,231)=24.71, p<.001$, partial $\eta^{2}=.18$. There was no significant effect of communication, consistent with $\mathrm{H} 2, F(1,231)=0.42$, $p=.519$, partial $\eta^{2}=.002$, nor was the interaction significant, $F(2,231)=0.20, p=.821$, partial $\eta^{2}=.002$. The effect of risk was followed up using Tukey's HSD. The low risk group $(M=31.88, S D=24.03)$ provided the lowest estimated probability of Mr. Wilson committing a new offence and significantly differed from the moderate $(M=45.43, S D=$ $21.95, p<.001, d=0.59,95 \% \mathrm{CI}[0.26,0.91])$ and high risk groups $(M=55.36, S D=$ $16.75, p<.001, d=1.15,95 \% \mathrm{CI}[0.81,1.49])$. The moderate risk group provided the next highest probability of recidivism and significantly differed from the high risk group $(p=.007, d=0.51,95 \%$ CI $[0.20,0.82])$. Finally, the high risk group provided the 
highest estimated probability of Mr. Wilson committing a new offence. Table 10 presents the ranges of responses provided across conditions. Overall, similar responses were provided for the low status quo $(M=33.68)$ and low Five-Levels $(M=29.79)$, moderate status quo $(M=46.31)$ and moderate Five-Levels $(M=44.58)$, and high status quo $(M=$ 55.20) and high Five Levels $(M=55.52)$. Overall, participants seem to overestimate risk when asked to provide it in a probability (0-100\%).

\section{Table 10}

Ranges of Responses Provided for Likelihood of Committing a New Crime Within Two Years

\begin{tabular}{lll}
\hline Risk Level & Stat Quo (M) & Five-Levels (M) \\
\hline Low & $3-98 \%(33.68)$ & $2-91 \%(29.79)$ \\
Mod & $10-100 \%(46.31)$ & $15-94 \%(44.58)$ \\
High & $15-100 \%(55.20)$ & $25-100 \%(55.52)$ \\
\hline
\end{tabular}

The last outcome to be analyzed in the risk-relevant hypotheses was how comfortable participants would be if Mr. Wilson was released (0-100\%). A two-way random-effects ANOVA was run and found no main effect of risk, $F(2,227)=2.74, p=$ .066 , partial $\eta^{2}=.02$, or communication format, $F(1,227)=0.80, p=.371$, partial $\eta^{2}=$ .004 , nor was there a significant interaction, $F(2,227)=0.83, p=.438$, partial $\eta^{2}=.007$.

Overall, results were consistent with $\mathrm{H} 1$, that there would be main effects of risk level, such that participants were able to differentiate low, moderate, and high risk across conditions. Similarly, the hypothesis suggesting there would be no effects of communication (H2) was also supported, such that there were no effects of communication format. The third hypothesis (H3), suggesting there would be an interaction between risk level and communication format, such that those in the Five- 
Levels group in the moderate risk condition would make lower risk decisions, was supported in one outcome: parole decisions.

\section{Consistency in Categorical Risk Rating}

No specific hypotheses were made regarding consistency ratings ${ }^{3}$. A binary logistic regression was used to examine the effects of risk level (low [reference category], moderate, high) and communication format (status quo [reference category], Five-Levels) on consistency in risk assignment $(0=$ not consistent with assigned risk level; $1=$ consistent with assigned risk level). The results can be found in Table 11. The overall model was significant, $\chi^{2}(5, N=238)=28.89, p<.001$. There was a significant effect of risk level, in which participants in the moderate risk condition, Wald $\chi^{2}(1)=13.31, p<$ .001 , and the high risk condition, Wald $\chi^{2}(1)=13.31, p<.001$, were significantly less likely to provide a consistent risk category compared to those in the low risk condition. There was also a significant interaction, Wald $\chi^{2}(1)=4.27, p=.039$, suggesting that those in the Five-Level condition (compared to the status quo condition) were more likely to provide consistent risk ratings when they were also in the moderate risk condition compared to the low risk condition. Figure 2 depicts the significant interaction and Figure 3 presents the consistency ratings across each group of the independent variables (risk level and communication format).

\footnotetext{
${ }^{3}$ Originally, both consistency questions were going to be run as ordinal logistic regressions, as both used a 5-point Likert scale. However, assumptions were violated, and the decision was made to recode both as consistent vs. not consistent and run a binomial logistic regression.
} 


\section{Table 11}

Logistic Regression for Consistency in Risk Rating

\begin{tabular}{llllll}
\hline & $\mathrm{R}^{2}$ & $\mathrm{~B}(\mathrm{SE})$ & $p$ & $\mathrm{OR}$ & $\mathrm{CI}(95 \%)$ \\
\hline Model & $.16^{* *}$ & & & & \\
5-Levels (vs. status quo) & & $-1.39(0.86)$ & .105 & 0.35 & $0.05,1.33$ \\
Moderate (vs. low) & & $-2.89(.79)$ & $<.001$ & 0.06 & $0.01,0.26$ \\
High (vs. low) & & $-1.99(0.80)$ & .013 & 0.14 & $0.29,0.65$ \\
5-L * Mod Risk & & $2.01(0.97)$ & .039 & 7.43 & $1.11,49.75$ \\
5-L * High Risk & & $0.68(0.97)$ & .484 & 1.97 & $0.30,13.10$ \\
\hline
\end{tabular}

Note. ${ }^{* *}$ denotes significance at $p<.01$.

\section{Figure 2}

Interaction Plot of Consistent Categorical Risk Decisions by Randomly Assigned Risk Level (Low, Moderate, High) and Separated by Communication Condition (Status Quo vs. Five-Levels)

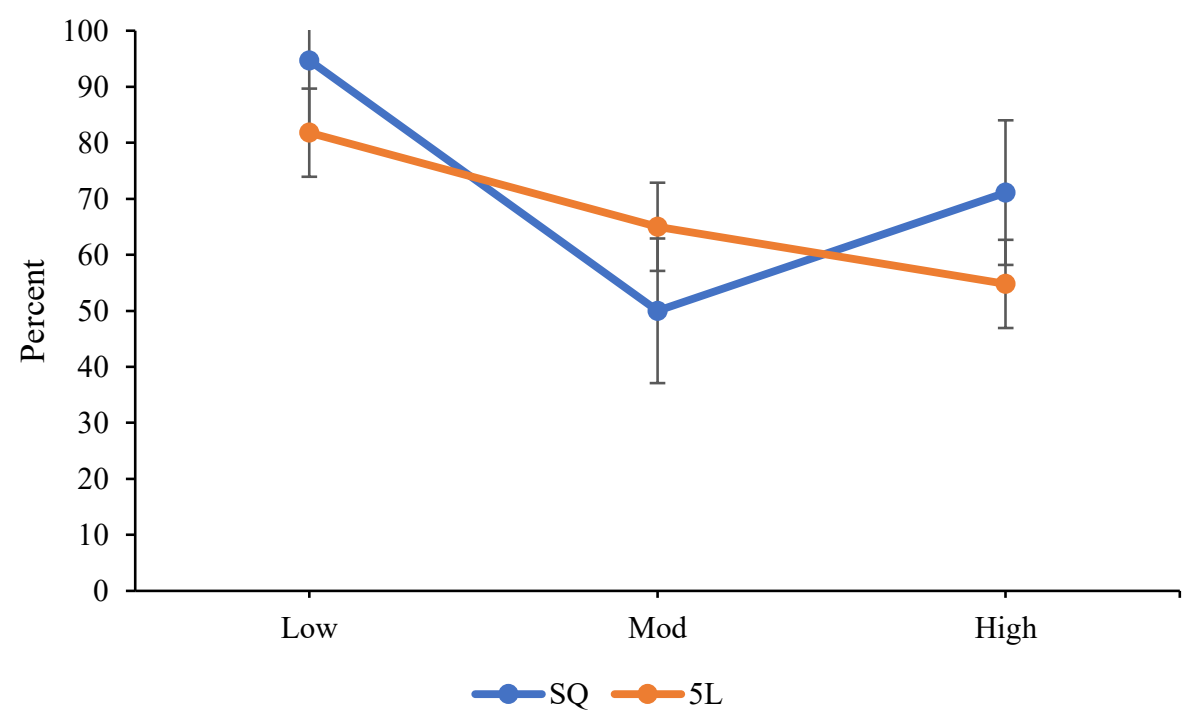

Note. $\mathrm{SQ}=$ Status quo, 5L = Five-Levels. Error bars represent standard errors. 


\section{Figure 3}

Breakdown of all Possible Assigned Risk Levels Separated by Each Condition

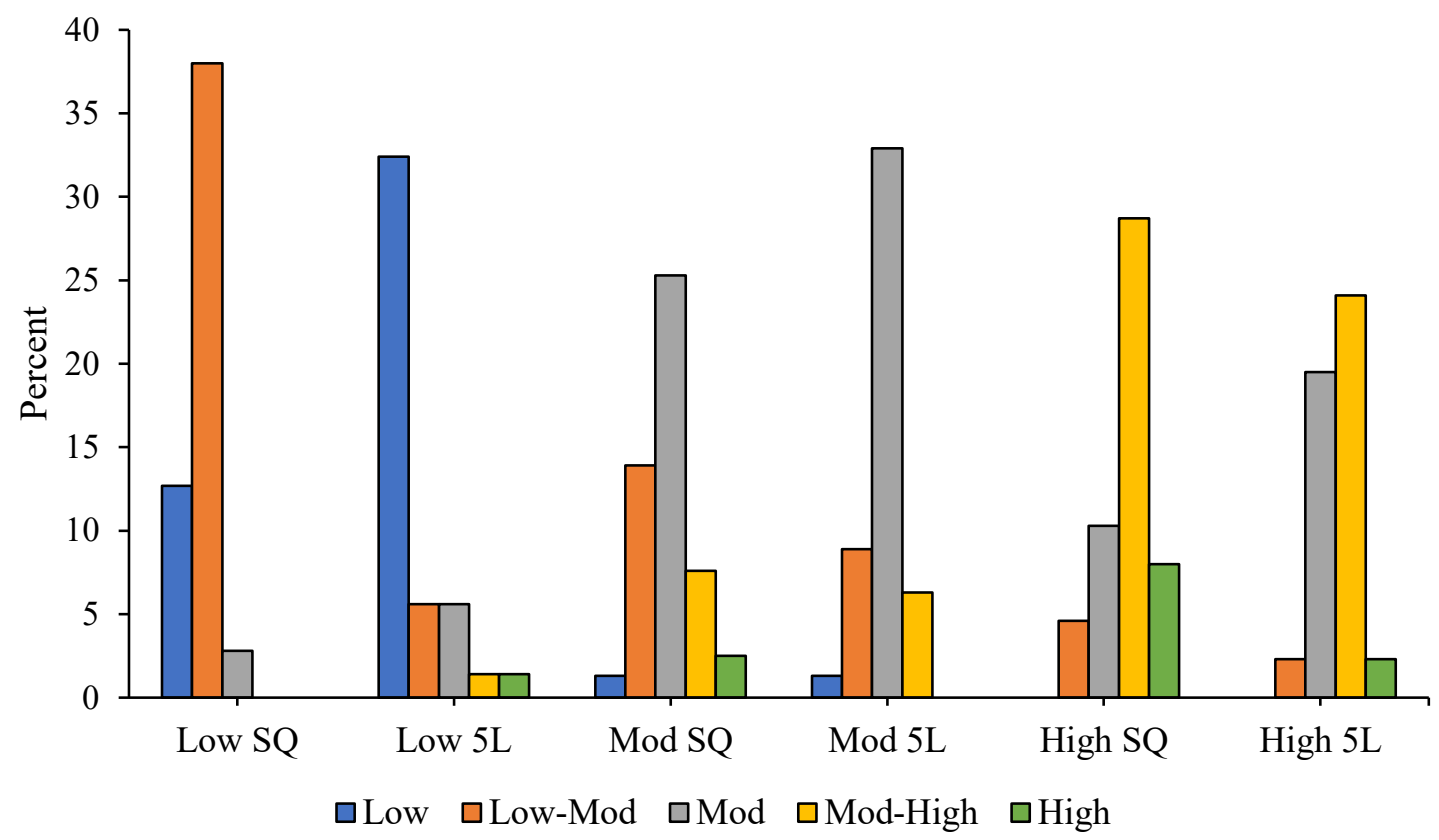

Note. $\mathrm{SQ}=$ status quo. $5 \mathrm{~L}=$ Five-Levels

\section{Consistency in Relative Risk Rating}

A binary logistic regression was used to examine the effects of risk level (low [reference category], moderate, high) and communication format (status quo [reference category], 5-Levels) on consistency in perceptions of relative risk $(0=$ not consistent, $1=$ consistent $)$. The overall model was significant, $\chi^{2}(5, N=238)=16.64, p=.005$. There was a significant main effect of risk level, such that those in the moderate risk condition were less likely to provide accurate risk predictions than those in the low risk condition, Wald $\chi^{2}(1)=9.41, p=.002$. Similarly, those in the high risk condition were also less likely to provide accurate risk predictions than those in the low risk condition, Wald $\chi^{2}(1)$ $=7.31, p=.007$. There was no significant effect of communication, Wald $\chi^{2}(1)=0.79, p$ 
$=.375$, nor was the interaction significant, Wald $\chi^{2}(1)=0.98, p=.614$. These results are displayed in Table 12.

\section{Table 12}

Logistic Regression for Relative Risk Ratings

\begin{tabular}{|c|c|c|c|c|c|}
\hline & $\mathrm{R}^{2}$ & $\mathrm{~B}(\mathrm{SE})$ & $p$ & OR & CI $(95 \%)$ \\
\hline Model & $.09 * *$ & & & & \\
\hline 5-Levels (vs. status quo) & & $-0.54(0.60)$ & .375 & 0.59 & $0.18,1.91$ \\
\hline Moderate (vs. low) & & $-1.67(0.55)$ & .002 & 0.19 & $0.06,0.55$ \\
\hline High (vs. low) & & $-1.45(0.54)$ & .007 & 0.23 & $0.08,0.67$ \\
\hline 5-L * Mod Risk & & $0.64(0.75)$ & .398 & 1.89 & $0.43,8.21$ \\
\hline 5-L * High Risk & & $0.70(0.74)$ & .348 & 2.01 & $0.47,8.61$ \\
\hline
\end{tabular}

Note. ${ }^{* *}$ denotes significance at $p<.01$.

\section{Treatment/Management Relevant Hypotheses (H4, H5, H6)}

A two-way random effects ANOVA was conducted to assess the effects of risk level (low, moderate, high) and communication format (status quo, Five-Levels) on the composite variable assessing attitudes toward treatment/management amenability (higher scores indicative of more positive attitudes towards Mr. Wilson). Consistent with H4, there was a main effect of risk, $F(2,231)=24.16, p<.001$, partial $\eta^{2}=.18$, as such Tukey's HSD was run to follow up this effect. Those in the low risk condition $(M=$ $18.61, S D=3.86$ ) had more positive attitudes on the composite treatment/management outcome than those in the moderate risk condition $(M=16.30, S D=3.69, p<.001, d=$ $0.61,95 \% \mathrm{CI}[0.28,0.94])$, and those in the high risk condition $(M=14.62, S D=3.90, p$ $<.001, d=1.03,95 \%$ CI $[0.69,1.36])$. Similarly, those in the moderate risk condition had more favourable attitudes than those in the high risk condition $(p=.007, d=0.44,95 \%$ CI $[0.13,0.75])$. Contrary to H5 and H6, there was no significant main effect of communication format, $F(1,231)=0.40, p=.529$, partial $\eta^{2}=.002$, nor was there an interaction between risk level and communication format, $F(2,231)=2.12, p=.122$, 
partial $\eta^{2}=.018$. Overall, only risk level seemed to influence perceptions of treatment amenability and risk management.

\section{Understandability/Importance Hypotheses (H7 and H8).}

A binary logistic regression was run to examine the effect of risk level (low [reference category], moderate, high) and communication format (status quo [reference category], Five-Levels) on understandability (no understandability issues vs. some understandability issues). The overall model was not significant, $\chi^{2}(5, N=237)=4.23, p$ $=.517$, nor were there effects of risk level, Wald $\chi^{2}(1)=1.17, p=.557$, communication format, Wald $\chi^{2}(1)=0.21, p=.650$, or the interaction, Wald $\chi^{2}(1)=0.41, p=.815$. Therefore, these results were consistent with H7 (no effect of risk level), but inconsistent with H8 (significant effect of communication format).

Two subsequent questions were asked tapping into understandability: did participants have enough information to determine Mr. Wilson's re-offending risk, and did participants have enough information to determine Mr. Wilson's parole decision. Two binary logistic regressions were run for these questions (Table 13). The overall model for having enough information for determining recidivism risk was significant, $\chi^{2}(5, N=238)=11.44, p=.043$. Inconsistent with $\mathrm{H} 7$, there was a significant main effect of risk level such that those in the high risk condition were less likely to say that they had enough information for determining Mr. Wilson's reoffence risk compared to participants in the low risk condition, Wald $\chi^{2}(1)=4.72, p=.030$. Contrary to H8, there was no significant effect of communication, Wald $\chi^{2}(1)=0.72, p=.789$, nor was there a significant interaction, Wald $\chi^{2}(1)=1.28, p=.527$. Similarly, the overall model for parole was also significant, $\chi^{2}(5, N=238)=23.78, p<.001$. Again, inconsistent with 
H7, there was a significant effect of risk Wald $\chi^{2}(1)=5.10, p=.024$, with no significant effect of communication, Wald $\chi^{2}(1)=0.06, p=.810$, nor a significant interaction, Wald $\chi^{2}(1)=5.93, p=.052$. The significant effect of risk level for both outcomes suggests that those in the high risk condition compared to the low risk condition were less likely to feel like there was enough information to determine both Mr. Wilson's recidivism risk and the parole decision. This was inconsistent with $\mathrm{H} 7$ and $\mathrm{H} 8$.

\section{Table 13}

Logistic Regressions for Enough Information Variables

\begin{tabular}{|c|c|c|c|c|c|}
\hline & $\mathrm{R}^{2}$ & $\mathrm{~B}(\mathrm{SE})$ & $p$ & OR & CI $(95 \%)$ \\
\hline Model: Re-offence & $.07 *$ & & & & \\
\hline $\begin{array}{l}\text { 5-Levels (vs. status } \\
\text { quo) }\end{array}$ & & $-0.17(0.63)$ & .789 & 0.84 & $0.24,2.92$ \\
\hline Moderate (vs. low) & & $-0.29(0.60)$ & .629 & 0.75 & $0.23,2.41$ \\
\hline High (vs. low) & & $-1.18(0.54)$ & .030 & 0.31 & $0.11,0.89$ \\
\hline 5-L * Mod Risk & & $0.98(0.91)$ & .283 & 2.67 & $0.44,16.00$ \\
\hline 5-L * High Risk & & $0.71(0.79)$ & .369 & 2.03 & $0.43,9.48$ \\
\hline Model: Parole & $.14 * *$ & & & & \\
\hline $\begin{array}{l}\text { 5-Levels (vs. status } \\
\text { quo) }\end{array}$ & & $-0.16(0.68)$ & .810 & 0.85 & $0.22,3.23$ \\
\hline Moderate (vs. low) & & $-1.04(0.59)$ & .079 & 0.35 & $0.11,1.13$ \\
\hline High (vs. low) & & $-1.29(0.57)$ & .024 & 0.28 & $0.09,0.84$ \\
\hline 5-L * Mod Risk & & $1.51(0.93)$ & .103 & 4.55 & $0.74,28.07$ \\
\hline 5-L * High Risk & & $-0.34(0.81)$ & .680 & 0.72 & $0.15,3.51$ \\
\hline
\end{tabular}

Three separate two-way random-effects ANOVAs were conducted to assess the effects of risk level (low, moderate, high) and communication format (status quo, FiveLevels) on the importance of each of new composite variables. Again, it was hypothesized that there would be no main effect of risk level $(\mathrm{H} 7)$ and significant main effect of communication format (H8) on ratings of importance. For the importance of Crime Severity/Criminal History information, there was no significant effect of risk level, $F(1,232)=0.43, p=.513$, communication format, $F(2,232)=0.48, p=.617$, or the 
interaction, $F(2,232)=0.86, p=.423$. Similar null findings were also reported for the importance of the Treatment/Opinion variable (risk level: $F(2,232)=0.70, p=.498$; communication format: $F(1,232)=0.01, p=.943$; interaction: $F(2,232)=0.30, p=$ $.740)$ and the Risk Assessment Information variable (risk level: $F(2,232)=0.80, p=$ .451 ; communication format: $F(1,232)=0.93, p=.335$; interaction: $F(2,232)=1.49, p$ $=.228)$. Overall, the average importance rating for each of the types of information were as follows: Crime Severity/Criminal History $(M=12.23, S D=2.22)$, Treatment/Opinion $(M=12.42, S D=2.09)$, and Risk Assessment Information $(M=15.74, S D=3.24)$. As the Crime Severity/Criminal History and Treatment/Opinion variables were assessed on a scale from 0-15, and Risk Assessment Information was assessed from 0-20, the average response suggests that overall participants found the information important in making their decisions.

Two qualitative questions were also utilized to assess understandability. In the first, participants were provided the opportunity to list up to three other factors they considered in making their decision and how important these factors were $(1=$ not at all important, 5 = very important). Overall, $26(10.9 \%)$ people provided a total of 42 responses. The main themes that emerged related to information about treatment $(n=11$, $26.2 \%)$, information about Mr. Wilson's mother being supportive of him $(n=7,16.6 \%)$, Mr. Wilson's behaviour while in prison $(n=7,16.6 \%)$, and his treatment and employment prospects $(n=5,11.9 \%)$. All information that was provided was rated as a 4 or 5 on the Likert scale, suggesting individuals felt the information was important or very important in making their decision. 
The final qualitative question asked if there was any other information that could have been provided to make their decision easier. A total of 127 responses were provided by 127 unique participants. Many responses suggested participants felt there was enough information provided ( $n=27,21.2 \%)$, while other themes that emerged included wanting more information from or about the victim $(n=7,5.5 \%)$, about Mr. Wilson continuing substance use treatment $(n=9,7.1 \%)$, hearing from Mr. Wilson himself $(n=13,10.2 \%)$, wanting information pertaining to Mr. Wilson's circle of friends and support outside of his mother $(n=9,7.1 \%)$, parole conditions or information $(n=8,6.3 \%)$, and overall probability of successful treatment and past successful treatment $(n=17,13.4 \%)$.

\section{Discussion}

In acknowledgement of the many issues prevalent in how risk is currently communicated, Hanson, Bourgon, and colleagues (2017) developed the Five-Level Risk and Needs System in an effort to improve consistency in risk communication. This system operates by providing a common language, base rates for recidivism, and a profile of an individual's risk and needs. Although promising, little research has been conducted to validate the utility of this system for making more consistent risk decisions. To address this limitation, the current study compared the risk decisions made by a sample of laypeople across two risk communication formats (Five-Levels and status quo) for a parole case involving a low, moderate, and high risk individual. The findings from the current study highlight the importance and ability of laypeople to distinguish between a low, moderate, and high risk justice-involved individual regardless of how risk was communicated. While the Five-Level system was hypothesized to influence treatment outcomes, limited support for this contention was found. This does not discredit the use 
of the Five-Level system but highlights the need for future research and potential finetuning of the system.

\section{Importance of Risk Level}

While the current study did not support many of the hypotheses regarding the Five-Levels, several important findings regarding risk level emerged. In regard to riskrelevant outcomes, it was hypothesized that there would be a main effect of assigned risk level, such that individuals would make decisions consistent with the risk-condition they received (low, moderate, and high). This finding was supported for parole decision, in which participants were less likely to grant parole as the individual's risk level increased. Other outcomes mirrored this finding, as participants in higher risk conditions suggested Mr. Wilson was more likely to reoffend within the next two years and had a higher probability of recidivism (0-100\%). Other studies have also shown support for participants being able to make decisions consistent with risk level, whether that be with a sample of laypeople (Helmus et al., 2018) or a sample of forensic clinicians (Hilton et al. 2017). Risk level also seemed to be the most salient factor for treatment/management perceptions, in that participants in lower risk conditions had more positive attitudes toward Mr. Wilson's amenability to treatment. Overall, in this study and with this sample of laypeople, the findings suggest that risk level appeared to matter more than how the information was communicated.

One potential explanation for the finding that risk seemed to be more salient than communication format could be due to the sample comprising of $\sim 30 \%$ professionals who indicated they use risk assessment in their professional lives. These individuals have probably received advanced training in risk assessment and are more apt to identify 
appropriate risk level based on case information. The increase in professionals with risk assessment experience was likely due to the method of data collection (being shared on Twitter amongst academic circles and amongst peers) and could have biased the results. It is unclear whether the current sample resembles laypeople that would make up a jury pool or those sitting on the Parole Board of Canada.

\section{Importance of Risk Communication Format}

As the intention of the Five-Levels is to provide a system that articulates a more complete picture of an individual, including treatment and supervision recommendations, it was expected that participants would have more positive opinions of Mr. Wilson, in terms of amenability and desistance, compared to participants in the status quo condition. This was the only main effect hypothesized for communication format. The current study, similar to Helmus and colleagues (2018), did not find support for this hypothesis. This result may be due to the relatively extensive information that was provided across both risk communication conditions. While past risk communication studies have only included short vignettes (often one paragraph), the current study utilized a full risk assessment report in order to enhance the external validity of the study. Both status quo and Five-Level conditions included extensive information regarding risk factors, strength-based factors, and treatment amenability, and this may account for the nonsignificant findings around the Five-Levels. Although the Five-Level system provides additional information concerning treatment amenability, these additional pieces of information may be overlooked due to processing demands, as the participants are already considering and interpreting numerous pieces of information. The cognitive literature has found that processing ability markedly decreases when individuals are 
tasked with making a decision with more than five to seven options (Cowen, 2001; Miller, 1956). The quantity of the information may have overshadowed the nuances and additional specificity provided in the Five-Level condition. Similarly, these nuanced additions may simply be ignored due to the already detailed nature of these reports. Heilbrun and colleagues (1999) found that the most valued risk communication format was one that included identified risk factors and specified interventions to target those factors, which all conditions received in the current study. However, these findings may also be due to risk information overriding information about treatment amenability, as risk level seemed to be more salient than how risk was communicated in making riskrelevant decisions.

The true benefit of the Five-Levels was hypothesised to occur in the interaction between risk level and communication format. Here it was expected that participants in the higher risk levels, particularly those in the moderate risk level, would more readily take into account information about treatment amenability and desistance, given that this information was made more salient in the Five-Levels condition. In turn, this would result in less punitive decision making. Unfortunately, there was very little support for this hypothesis. The only significant interaction resulted from parole decisions. Those in the Five-Level moderate risk condition were more likely to make lower risk decisions than those in the status quo moderate risk condition. While Helmus and colleagues (2018) simply had high and low risk, the inclusion of moderate risk in the current study allowed for more variation or fluctuations in decisions, and relying upon other information (e.g., treatment). While assigned risk level was more important in participant perceptions and ratings of treatment/management potential (how likely Mr. Wilson is to comply with 
parole, benefit from treatment, lower risk of recidivism, stay crime free, desist from crime), risk communication format was important in making the ultimate decision to release Mr. Wilson. For those in the moderate risk condition, where it is not necessarily clear how Mr. Wilson will fare in the community, it appears that information included in the Five-Levels (especially in the overall opinion section at the end of the assessment) may have led to participants feeling more comfortable releasing Mr. Wilson on parole. This is encouraging, that the Five-Levels may provide important additional information for making decisions for individuals where the prognosis is less clear; when an individual is described as low risk or high risk, the ultimate decision may be simpler (grant or deny parole, respectively).

The presence of an interaction for parole decision may also be due to the order the outcomes were presented, with parole decision being the first outcome participants answered. The last piece of information in the risk assessment participants read was the overall opinion of risk, which for the Five-Levels gives a prognosis and number of hours of treatment required to progress to a lower risk level. This may coincide with the availability heuristic (Tversky \& Kahneman, 1974), in which biases can occur due to the salience of information. Salience may indicate that more recent information can be more easily recalled (Tversky \& Kahneman, 1974). Since parole was the first outcome, participants may have relied solely on the most recent information they were given, where subsequent outcomes could have allowed participants more time to consider other factors (e.g., riskiness, the nature of the crime, etc.) which may have led to more conservative decisions. 


\section{Other Notable Findings}

While no specific hypotheses were made regarding consistency of risk decisions, notable findings emerged. A significant interaction was found, in which those in the FiveLevel moderate risk condition were more likely to provide consistent risk ratings than those in the status quo moderate risk condition. Similar to the interaction for parole decision, this may be the result of variability around moderate risk, allowing for fluctuations and for other information to be considered. In the decision-making literature, the anchoring effect occurs when individuals are overly influenced by the first piece of information they encounter (Tversky \& Kahneman, 1974). One of the first pieces of information that participants received when reading the assessment was that Mr. Wilson committed a violent offence. The significant interaction among consistency ratings may provide preliminary evidence that the Five-Levels helps to overcome this bias. The interaction may also be due to the ordering of the questions, similar to the parole outcome, participants were asked to provide a categorical risk level directly after being asked about parole. This may again indicate that the salience of the information provided at the end of the risk assessment was what participants were basing their decision off of (Tversky \& Kahneman, 1974). Further research is needed to examine the source of these differences.

There was also a significant effect of risk level on consistency decisions, suggesting those in the moderate and high risk conditions were less likely to choose a consistent risk category than those in the low risk condition. This finding may be related to the main effect of risk seen for the confidence rating; as risk level increased, confidence in decision-making decreased. Similarly, here it can be seen that as risk level 
increases, consistency decisions decrease. For these outcomes, it seems there is less confidence in decision making, the higher the risk level. Those in the high risk condition were less consistent, less confident, and felt they needed more information to make their decisions. These individuals may feel that the stakes are higher when making these risk decisions, resulting in lower confidence. Confidence in decisions has been shown to be related to accuracy both within clinical risk assessment settings (McNeil et al., 1998), and within the eyewitness literature (Wixted et al., 2015), suggesting those who report higher confidence ratings are more accurate.

Another notable and concerning finding is that participants still tended to overestimate risk. Ranges that were provided to participants for recidivism risk in each condition were as follows: low: 3-32\%, moderate: $13-45 \%$, and high: $41-60 \%$. Ranges that were provided by participants were much greater: low: $2-98 \%$, moderate: $10-100 \%$, and high: $15-100 \%$. Other studies have found laypeople overestimate risk when asked to provide risk as a probability (Batastini et al., 2018). However, the current study, unlike past studies, gave extensive information in all conditions, rather than simply giving a categorical label (Evans \& Salekin, 2016; Mills \& Kroner, 2006). Despite additional information provided and despite being told the actual ranges for the individual, participants still overestimated his level of risk. This may be due to not understanding numerical data, as several studies have shown laypeople find this challenging (Batastini et al., 2018; Krauss \& Lee, 2003; Slovic \& Monahan, 1995), or it may be that people's heuristics are overriding information presented to them.

When individuals are asked probabilistic questions, they often rely on the representativeness heuristic, or the mental shortcut in which the probability of something 
occurring is based on similarity to presumed related event (Tversky \& Kahneman, 1974). This heuristic often results in base rate neglect or ignoring the frequency of an event actually occurring (Neal \& Grisso, 2014). It may also be that their availability heuristic is unable to be overridden. Availability refers to how easily someone can recall information based on other examples of the event (Neal \& Grisso, 2014), therefore if an individual heard in the media how dangerous people are who commit crime, or if they have experienced crime in their lives, they may assume all people who commit crimes are "bad" and high risk. Research on heuristics and decision-making may help to explain why individuals overestimate risk, as their mental shortcuts may override the information they received in the risk assessment report.

\section{Understandability and Importance}

Regarding understandability outcomes, no significant effects were found, despite hypothesizing there would be a significant effect of communication. This could be due to the length of the risk assessment reports (3.5 pages), as they were made in the likeness of true reports used by professionals. Similar studies have presented much shorter reports (e.g., 1-2 paragraphs; Helmus et al., 2018). Overall ratings of importance for each composite variable were high, suggesting that most of the information presented in the assessments was deemed important when making decisions about Mr. Wilson.

When asked if there was other information that participants considered when making their decision, they suggested treatment information, support, and behaviour in prison were all very important. When asked if there was other information that could have been provided to make their decisions easier, participants were able to identify many criminogenic needs/risk factors, including wanting information about substance use 
treatment, Mr. Wilson's support and friend group, and past success in treatment. Few people identified information that was not pertinent for risk assessment considerations including wanting information from the victim (i.e., victim impact statement). The ability to identify criminogenic needs may have been due, again, to roughly $30 \%$ of the sample representing professionals in the field of risk assessment. Future research should utilize a more representative sample from the general public.

\section{Limitations}

While this was one of the first studies to examine the effectiveness of the FiveLevel system, some limitations need to be considered. Overall, generalizability from the sample may be problematic, as the sample consisted of $\sim 77 \%$ women, $\sim 90 \%$ Caucasian, and $\sim 30 \%$ professionals. The sample was also highly educated, with the majority of the sample having at least a bachelor's degree. This is most likely due to the method of data collection, as the survey was shared on Twitter and Facebook amongst fellow academics and students. Future studies should consider more representative samples of the general public, and a separate sample of professionals.

Additionally, despite providing an extensive and more comprehensive risk assessment, this cannot replace the testimony and other information that may be presented or included in a given case. I also presented consistent information across the risk scales, in which they all came to the same conclusion, while often true risk scales present discrepant information (Barbaree et al., 2006; Jung et al., 2013). One of the strengths of the Five-Levels may lie in bridging discrepant risk scale information. Future studies should assess whether the Five-Levels increases consistency in decisions when risk scales give discrepant information. 


\section{Implications and Conclusion}

The field of risk communication has not quite determined how best to communicate risk for the past two decades (Heilbrun et al., 1999), with the Five-Level system development aiming to address and overcome many of these issues. The current study found little evidence that communication in line with the Five-Level system does much to aid individuals in their decision-making regarding a justice-involved individual. Although the Five-Level system presents a promising contribution to the presentation and communication of risk relevant information, the current findings suggest further research and fine-tuning is required to ensure the utility of the system.

While the Five-Levels have been applied to numerous risk assessment tools for various types of offending behaviour, there may be limitations of the Five-Level system itself, with adjustment needed going forward (Hogan, 2020). For example, while there has been substantial evidence of common risk factors among all individuals who offend (i.e., the Central Eight; Andrews et al., 2006) there are also certain risk factors that are more associated with different types of offending behaviour (e.g., sexual offences, violent offences, etc.). As such, the risk and needs profiles of those who commit different types of offences are different than the risk/needs profile of those who commit general offences that the Five-Levels were designed to accommodate. The rates of recidivism may also differ for individuals who commit differing offences. Considering this, the Five-Levels may be unable to accommodate for specialized offending behaviour, especially given that differing risk instruments may assess different facets of a certain behaviour (Barbaree et al., 2006; Hogan, 2020). 
Hogan (2020) suggests that the Five-Levels can be used for specialized offending if there is clear articulation of the meaning of the levels within each specialized context. For example, in the current study I assessed an individual who committed a violent offence (assault and robbery) with general recidivism tools. The Five-Levels here speak to Mr. Wilson's risk of general recidivism only, it cannot speak to his potential for violent recidivism. As more tools adapt to the Five-Level system, differing tools could be used to tap into differing types of recidivism, and therefore could be specified that (for example) an individual scored a Level III on general recidivism and a Level II on violent recidivism. For a more complete review of limitations of the Five Levels see Hogan (2020).

Further studies examining which information is being utilized to make relevant risk, treatment, and parole decisions could aid in efforts to ensure that the Five-Level system not only standardizes risk decisions but also leads to more consistent decisions concerning such risk. Specifically, efforts in future studies to address cognitive biases and limitations in processing (e.g., reliance on heuristics) may serve to improve the system by adjusting the presentation of information. The lack of support for some hypotheses may reflect less so shortcomings in the Five-Level system and speak more so to the level of detail provided. In real life circumstances, it is not uncommon for risk decisions to be based upon numerous factors as evident from the current study and others (Blais \& Forth, 2014; Evans \& Salekin, 2014; Storey et al., 2013; Viljoen et al., 2010). Therefore, it is possible that the Five-Level system is unable to accommodate such levels of information in a streamlined package in which audiences can accurately focus on the most salient information. For example, the cognitive literature has shown individuals can make 
decisions based on no more than between three and seven pieces of information (Cowen, 2001; Miller, 1956). If the Five-Levels provides more information than this, it could result in similar pitfalls of status quo communication (e.g., base rate neglect). Again, future research should consult the cognitive literature in order to design a study testing whether the Five-Levels could overcome certain heuristics.

While the current study did not find overall support for the Five-Levels, it is premature to make any conclusions about the utility of the system based on the limited studies that have been done (Helmus et al., 2018). Positive findings from the current study include participants making better parole decisions and more consistent risk rating decisions for those in the Five-Levels moderate risk condition. The current study also highlights limitations within the Five-Levels and points to the need to consult other research areas such as cognitive psychology and the decision-making literature. Future studies should specifically examine how the Five-Levels can improve decision-making, consulting and utilizing outcomes that specifically tap into cognitive heuristics. Future research should also consider using samples of professionals who use and make risk decisions in their professional lives. Despite limitations, the Five-Levels have the ability to standardize and provide non-arbitrary metrics to describe justice-involved individuals, which can aid in rehabilitation, cutting costs to the system, and providing meaningful change in these individual's lives (Hanson, Bourgon et al., 2017). 


\section{References}

Andrews, D.A., \& Bonta, J. (1995). The Level of Service Inventory-Revised. Toronto, Canada: Multi-Health Systems

Andrews, D., Bonta, J., \& Wormith, J. (2006). The recent past and near future of risk and/or need assessment. Crime and Delinquency, 52(1), 7-27. https://doi.org/10.1177/0011128705281756

Andrews, D. A., \& Bonta, J. (2010). The psychology of criminal conduct (5th ed.). Albany, N.Y.

Andrews, D. A., Zinger, I., Hoge, R. D., Bonta, J., Gendreau, P., \& Cullen, F. T. (1990). Does correctional treatment work? A psychologically informed meta-analysis. Criminology, 28(3), 369-404. https://doi.org/10.1111/j.17459125.1990.tb01330.x

Attali, Y. \& Bar-Hillel, M. (2003). Guess where: The position of correct answers in multiple-choice test items as a psychometric variable. Journal of Educational Measurement, 40(2), 109-128. https://doi.org/10.1111/j.17453984.2003.tb01099.x

Bakker, M., \& Wicherts, J. (2014). Outlier removal and the relation with reporting errors and quality of psychological research. PloS One, 9(7). https://doi.org/10.1371/journal.pone.0103360

Barbaree, H., Langton, C., \& Peacock, E. (2006). Different actuarial risk measures produce different risk rankings for sexual offenders. Sexual Abuse, 18(4), 423440. https://doi.org/10.1177/107906320601800408 
Batastini, A. B., Hoeffner, C. E., Vitacco, M. J., Morgan, R. D., Coaker, L. C., \& Lester, M. E. (2018). Does the format of the message affect what is heard? A two-part study on the communication of violence risk assessment data. Journal of Forensic Psychology Research and Practice, 19(1), 44-71. https://doi.org/10.1080/24732850.2018.1538474

Batastini, A., Vitacco, M., Coaker, L., \& Lester, M. (2019). Communicating violence risk during testimony: Do different formats lead to different perceptions among jurors? Psychology, Public Policy, and Law, 25(2), 92-106.

https://doi.org/10.1037/law0000196

Blais, J., \& Forth, A. (2014). Prosecution-retained versus court-appointed experts:

Comparing and contrasting risk assessment reports in preventative detention hearings. Law and Human Behavior, 38(6), 531-543.

https://doi.org/10.1037/lhb0000082

Bonta, J., \& Andrews, D. (2017). The psychology of criminal conduct. Taylor \& Francis.

Borum, R., Otto, R., \& Golding, S. (1993). Improving clinical judgment and decision making in forensic evaluation. The Journal of Psychiatry \& Law, 21(1), 35-76. https://doi.org/10.1177/009318539302100104

Christenfeld, N. (1995). Choices from identical options. Psychological Science, 6(1), 5055. https://doi.org/10.1111/j.1467-9280.1995.tb00304.x

Conroy, M. A., \& Murrie, D. C. (2007). Forensic assessment of violence risk: A guide for risk assessment and risk management. Wiley. https://doi.org/10.1002/9781118269671 
Cowan, N. (2001). The magical number 4 in short-term memory: A reconsideration of mental storage capacity. The Behavioral and Brain Sciences, 24(1), 87-114. https://doi.org/10.1017/S0140525X01003922

Dolores, J. C., \& Redding, R. E. (2009). The effects of different forms of risk communication on judicial decision making. International Journal of Forensic Mental Health, 8(2), 142-146. https://doi.org/10.1080/14999010903199407

Dowden, C., \& Andrews, D. (1999a). What works for female offenders: A meta-analytic review. Crime and Delinquency, 45(4), 438-452. https://doi.org/10.1177/0011128799045004002

Dowden, C., \& Andrews, D. A. (1999b, May). What works in young offender treatment: A meta-analysis. In Forum on corrections research (Vol. 11, pp. 21-24). Correctional Service of Canada. Retrieved from https://www.ncjrs.gov/App/Publications/abstract.aspx?ID=181332

Dowden, C., \& Andrews, D. A. (2000). Effective correctional treatment and violent reoffending: A meta-analysis. Canadian Journal of Criminology, 42(4), 449-467.

Doyle, D., Ogloff, J., \& Thomas, S. (2011). Designated as dangerous: Characteristics of sex offenders subject to post-sentence orders in Australia. Australian Psychologist, 46(1), 41-48. https://doi.org/10.1111/j.1742-9544.2010.00006.x Ægisdóttir, S., White, M., Spengler, P., Maugherman, A., Anderson, L., Cook, R., Nichols, C., Lampropoulos, G., Walker, B., Cohen, G., \& Rush, J. (2016). The meta-analysis of clinical judgment project: Fifty-six years of accumulated research on clinical versus statistical prediction. The Counseling Psychologist, 34(3), 341-382. https://doi.org/10.1177/0011000005285875 
Elbogen, E. (2002). The process of violence risk assessment: A review of descriptive research. Aggression and Violent Behavior, 7(6), 591-604. https://doi.org/10.1016/S1359-1789(01)00051-9

Evans, S. A., \& Salekin, K. L. (2014). Involuntary civil commitment: Communicating with the court regarding "danger to other". Law and Human Behavior, 38(4), 325336. https://doi.org/10.1037/lhb0000068

Evans, S. A., \& Salekin, K. L. (2016). Violence risk communication: What do judges and forensic clinicians prefer and understand? Journal of Threat Assessment and Management, 3(3-4), 143-164. https://doi.org/10.1037/tam0000062

Faul, F., Erdfelder, E., Lang, A.G., \& Buchner, A. (2007). G*Power 3: A flexible statistical power analysis program for the social, behavioral, and biomedical sciences. Behavior Research Methods, 39, 175-191

Grove, W., Zald, D., Lebow, B., Snitz, B., \& Nelson, C. (2000). Clinical versus mechanical prediction: A meta-analysis. Psychological Assessment, 12(1), 19-30. https://doi.org/10.1037/1040-3590.12.1.19

Hair, J.F, Tatham, R.L, Anderson, R.E \& Black, W. (1998) Multivariate data analysis. (Fifth Ed.) Prentice-Hall.

Hanson, K. R., Babchishin, K. M., Helmus, M. L., Thornton, D., \& Phenix, A. (2017). Communicating the results of criterion referenced prediction measures: Risk categories for the static-99R and static-2002R sexual offender risk assessment tools. Psychological Assessment, 29(5), 582-597.

https://doi.org/10.1037/pas000037 
Hanson, K. R., Bourgon, G., McGrath, R. J., Kroner, D., D’Amora, D. A., Thomas, S. S., Tavarez, P. (2017). A five-level risk and needs system: Maximizing assessment results in corrections through the development of a common language.

Hanson, RK, Bourgon, G, Helmus, L, \& Hodgson, S. (2009). The principles of effective correctional treatment also apply to sexual offenders: A meta-analysis. Criminal Justice and Behavior, 36(6), 865-891. https://doi:10.1177/0093854809338545

Hare, R. D. (2003). Manual for the Hare Psychopathy Checklist (Revised 2nd ed.). MultiHealth Systems.

Hathaway, S. R., \& McKinley J. C. (1989). Manual for the Minnesota Multiphasic Personality Inventory. Minneapolis: University of Minnesota Press.

Heilbrun, K., O’Neill, M.L., Stevens, T.N., Strohman, L.K., Bowman, Q., \& Lo, Y.-W. (2004). Assessment normative approaches to communicating violence risk: A national survey of psychologists. Behavioral Sciences and the Law, 22, 187-196. https://doi.org/10.1002/bsl.570

Heilbrun, K., Philipson, J., Berman, L., \& Warren, J. (1999). Risk communication: Clinician reported approaches and perceived values. Journal of the American Academy of Psychiatry and the Law, 27, 397-406.

Helmus, M. (2018, August 30). Symposium: Advancing a common language for offender risk communication: The Justice Center's Standardized 5-Level Risk/Needs System [PowerPoint slides] Presented at the International Association for the Treatment of Sexual Offenders.

Hilton, Z. N., Carter, A. M., Harris, G. T., \& Sharpe, A. J. B. (2008). Does using nonnumerical terms to describe risk aid violence risk communication?: Clinician 
agreement and decision making. Journal of Interpersonal Violence, 23(2), 171188. https://doi.org/10.1177/0886260507309337

Hilton, N., Ham, E., Nunes, K., Rodrigues, N., Frank, C., \& Seto, M. (2017). Using graphs to improve violence risk communication. Criminal Justice and Behavior, 44(5), 678-694. https://doi.org/10.1177/0093854816668916

Hilton, N. Z., Harris, G. T., Rawson, K., \& Beach, C. A. (2005). Communicating violence risk information to forensic decision makers. Criminal Justice and Behavior, 32(1), 97-116. https://doi.org/10.1177/0093854804270630

Hogan, N. (2020). Critical considerations in the development and interpretation of common risk language. Psychiatry, Psychology, and Law, 1-17. https://doi.org/10.1080/13218719.2020.1767719

Jung, S., Pham, A., \& Ennis, L. (2013). Measuring the disparity of categorical risk among various sex offender risk assessment measures. Journal of Forensic Psychiatry \& Psychology, 24(3), 353-370. https://doi.org/10.1080/14789949.2013.806567

Kaiser, H. (1960). The application of electronic computers to factor analysis. Educational and Psychological Measurement, 20(1), 141-151. https://doi.org/10.1177/001316446002000116

Kraemer, H. C., Kazdin, A. E., Offord, D. R., Kessler, R. C., Jensen, P. S., \& Kupfer, D. J. (1997). Coming to terms with the terms of risk. Archives of General Psychiatry, $54,337-343$.

Krauss, D. A., Cook, G. I., \& Klapatch, L. (2018). Risk assessment communication difficulties: An empirical examination of the effects of categorical versus 
probabilistic risk communication in sexually violent predator decisions. Behavioral Sciences \& the Law, 36(5), 532-553. https://doi.org/10.1002/bs1.2379

Krauss, D. A., \& Lee, D. H. (2003). Deliberating on dangerousness and death: Jurors' ability to differentiate between expert actuarial and clinical predictions of dangerousness. International Journal of Law and Psychiatry, 26(2), 113137. https://doi.org/10.1016/S0160-2527(02)00211-X

Laerd Statistics (2017). Two-way ANOVA using SPSS Statistics. Statistical tutorials and software guides. Retrieved from https://statistics.laerd.com/

Lowder, E. M., Morrison, M. M., Kroner, D. G., \& Desmarais, S. L. (2019). Racial bias and LSI-R assessments in probation sentencing and outcomes. Criminal Justice and Behavior, 46(2), 210-233. https://doi.org/10.1177/0093854818789977

McNiel, D., Sandberg, D., \& Binder, R. (1998). The relationship between confidence and accuracy in clinical assessment of psychiatric patients' potential for violence. Law and Human Behavior, 22(6), 655-669. https://doi.org/10.1023/A:1025754706716 Miller, G. (1956). The magical number seven, plus or minus two: Some limits on our capacity for processing information. Psychological Review, 101(2), 343-352. https://doi.org/10.1037/0033-295X.101.2.343

Mills, J. F., \& Kroner, D. G. (2006). The effect of base-rate information on the perception of risk for reoffense. American Journal of Forensic Psychology, 24(3), 45-56.

Monahan, J., \& Silver, E. (2003). Judicial decision thresholds for violence risk management. International Journal of Forensic Mental Health, 2(1), 1-6. https://doi.org/10.1080/14999013.2003.10471174 
Murray, J., \& Thomson, D. (2010). Applying decision making theory to clinical judgements in violence risk assessment. Europe's Journal of Psychology, 6(2), 150-171. https://doi.org/10.5964/ejop.v6i2.189

Neal, T., \& Grisso, T. (2014). The cognitive underpinnings of bias in forensic mental health evaluations. Psychology, Public Policy, and Law, 20(2), 200-211. https://doi.org/10.1037/a0035824

Nuffield, J. (1982). Parole decision-making in Canada: Research towards decision guidelines. Ottawa: Solicitor General of Canada.

Olver, M., Mundt, J., Thornton, D., Beggs Christofferson, S., Kingston, D., Sowden, J., Nicholaichuk, T., Gordon, A., \& Wong, S. (2018). Using the Violence Risk Scale-Sexual Offense version in sexual violence risk assessments: Updated risk categories and recidivism estimates from a multisite sample of treated sexual offenders. Psychological Assessment, 30(7), 941-955. https://doi.org/10.1037/pas0000538

Scurich, N. (2018). The case against categorical risk estimates. Behavioral Sciences \& the Law, 36(5), 554-564. https://doi.org/10.1002/bsl.2382

Scurich, N., \& Krauss, D. A. (2014). The presumption of dangerousness in sexually violent predator commitment proceedings. Law, Probability and Risk, 13(1), 91104. https://doi.org/10.1093/lpr/mgt015

Scurich, N., \& John, R. S. (2010;2011;). The effect of framing actuarial risk probabilities on involuntary civil commitment decisions. Law and Human Behavior, 35(2), 8391. https://doi.org/10.1007/s10979-010-9218-4 
Shaw, J., Bergen, J., Brown, C., \& Gallagher, M. (2000). Centrality preferences in choices among similar options. The Journal of General Psychology, 127(2), 157164. https://doi.org/10.1080/00221300009598575

Singh, J., Desmarais, S., Hurducas, C., Arbach-Lucioni, K., Condemarin, C., Dean, K., Doyle, M., Folino, J., Godoy-Cervera, V., Grann, M., Ho, R., Large, M., Nielsen, L., Pham, T., Rebocho, M., Reeves, K., Rettenberger, M., de Ruiter, C., Seewald, K., \& Otto, R. (2014). International perspectives on the practical application of violence risk assessment: A Global Survey of 44 Countries. International Journal of Forensic Mental Health, 13(3), 193-206.

https://doi.org/10.1080/14999013.2014.922141

Slovic, P., \& Monahan, J. (1995). Probability, danger, and coercion: A study of risk perception and decision making in mental health law. Law and Human Behavior, 19(1), 49-65. https://doi.org/10.1007/BF01499072

Slovic, P., Monahan, J., \& MacGregor, D. G. (2000). Violence risk assessment and risk communication: The effects of using actual cases, providing instruction, and employing probability versus frequency formats. Law and Human Behavior, 24(3), 271-296. https://doi.org/10.1023/A:1005595519944

Storey, J., Campbell, V., \& Hart, S. (2013). Expert Evidence About Violence Risk Assessment: A Study of Canadian Legal Decisions. International Journal of Forensic Mental Health, 12(4), 287-296. https://doi.org/10.1080/14999013.2013.867383

Tabachnick, B., \& Fidell, L. (2013). Using multivariate statistics (Pearson New International ed.). Pearson Education. 
Tversky, A., \& Kahneman, D. (1973). Availability: A heuristic for judging frequency and probability. Cognitive Psychology, 5(2), 207-232. https://doi.org/10.1016/00100285(73)90033-9

Tversky, A., \& Kahneman, D. (1974). Judgment under uncertainty: Heuristics and biases. Science (American Association for the Advancement of Science), 185(4157), 1124-1131. https://doi.org/10.1126/science.185.4157.1124

Varela, J. G., Boccaccini, M. T., Cuervo, V. A., Murrie, D. C., \& Clark, J. W. (2014). Same score, different message: Perceptions of offender risk depend on static-99R risk communication format. Law and Human Behavior, 38(5), 418-427. https://doi.org/10.1037/lhb0000073

Viljoen, J. L., McLachlan, K., \& Vincent, G. M. (2010). Assessing violence risk and psychopathy in juvenile and adult offenders: A survey of clinical practices. Assessment, 17(3), 377-395. https://doi.org/10.1177/1073191109359587

Ward, T., \& Stewart, C. (2003). The treatment of sex offenders: Risk management and good lives. Professional Psychology: Research and Practice, 34(4), 353-360. https://doi.org/10.1037/0735-7028.34.4.353

Webster, C. D., Douglas, K. S., Eaves, D., \& Hart, S. D. (1997). Assessing risk for violence - Version 2. Burnaby, Canada: Mental Health, Law, and Policy Institute, Simon Fraser University.

Wixted, J., Mickes, L., Clark, S., Gronlund, S., \& Roediger, H. (2015). Initial eyewitness confidence reliably predicts eyewitness identification accuracy. The American Psychologist, 70(6), 515-526. https://doi.org/10.1037/a0039510 


\section{Appendix A: Informed Consent}

\section{Carleton \\ U N I V E R S I T Y \\ Canada's Capital University}

Title: Testing a new non-arbitrary system for risk communication

Date of ethics clearance: May $7^{\text {th }}, 2020+$ CUREB-B Clearance 112785

Purpose: The goal of this study is to determine if different ways of presenting information in a risk assessment report results in differences in risk decisions related to a parole case.

Task requirements: In this 15-minute anonymous online survey you will read a mock risk assessment and be asked questions after about whether or not you would grant the mock offender parole, and how likely he is to commit a new crime, among several other risk related questions. The principal researcher for this study is Meghan Garvey from the Department of Psychology at Carleton University.

Eligibility: Adult (18 years + ); can read and write in English

Potential risks: There are no anticipated risks to this study. The violence offence described is similar in content to what would be reported on the news

Benefits/compensation: Each person will be entered into a draw to win a \$100 Amazon gift card. Responses from you and others will also provide valuable information about the best method to communicate risk, which can inform future practice.

Anonymity/confidentiality: No identifying information will be collected in the survey and no other information that could be used to identify you can be connected with your survey responses, so your answers will be anonymous. If you want to be considered for the draw, you will be re-directed to a separate page to provide your email address. Note that your email address cannot be linked to your survey responses.

Right to withdraw: Your participation in this study is entirely voluntary. You may withdraw your participation at any point, and you have the right to refuse to complete certain questions without penalty. Should you decide to withdraw before completing the study, close the survey window and we will delete your data. However, please note that it will be impossible to withdraw your participation after you have completed the survey because your responses are anonymous, and we will not be able to identify which responses were yours. 
Once the project is completed, all research data will be kept indefinitely and potentially used for other projects on this same topic or for teaching purposes. A subsequent data set, stripped of all potential identifying information, may subsequently be made available to other researchers again solely for academic purposes. If you would like a copy of the finished research project, you are invited to contact the researcher to request an electronic copy which will be provided to you.

Concerns: If you have any questions or concerns about this study, please contact Dr. Julie Blais, at Julie.blais@carleton.ca, or Meghan Garvey, at meghan.garvey@carleton.ca.

The ethics protocol for this project was reviewed and cleared by the Carleton University Research Ethics Board-B. If you have any ethical concerns with the study, please contact CUREB-B (by phone at 613-520-2600 ext. 4085 or via email at ethics@,carleton.ca).

By clicking "submit", you consent to participate in the research study as described above. 


\section{Appendix B: Mock Risk Assessments}

\section{HIGH RISK VIGNETTE - Five-Levels}

Nearly all prisoners will eventually be released. Some prisoners may be paroled which means they are released from prison to serve the last part of their sentence in the community. Their release is supervised by correction's officers and they can get some help with things like mental health and substance abuse. They also need to obey certain rules. If they break any of these rules, they could be sent back to prison for the rest of their sentence.

You are tasked with reviewing the following report which has been prepared by a registered clinician in order to help the parole board in deciding whether Mr. Darrell Wilson should be released to serve the last part of his sentence in the community. Once you have read the report, you will be asked for your opinion concerning Mr. Wilson's parole hearing.

\section{In reading the following assessment, you can assume that the psychologist is a qualified expert and that all measures of risk used are accepted within the field.}

\section{Evaluation Report}

Report written by: Dr. John Campbell

Name: Darrell Wilson

Age: 43

Offenses: Assault; Robbery

I have been asked to complete a psychological risk assessment for Mr. Darrell Wilson. Mr. Wilson is currently serving a 2.5-year sentence for assault and robbery. Mr. Wilson is now eligible for parole after serving two-thirds of his sentence in a federal institution. This report is meant to aid the parole board in making their release decision.

I met with Mr. Wilson over the course of three separate sessions. In total, I spoke with Mr. Wilson for just over 6 hours. I also had access to the following records in order to confirm information provided by Mr. Wilson: law enforcement records (e.g., arrest reports), past mental health evaluations, correctional assessments (e.g., behaviour reports from past incarcerations), and court transcripts.

\section{Current Offense}

Mr. Wilson was convicted of assault and robbery following a jury trial in January 2018. These events occurred in December 2016. Mr. Wilson had been drinking and smoking crack cocaine with a number of others in the basement of a house known to be used as a drug/party house. At some point, a confrontation occurred between Mr. Wilson and the victim, Kyle Richards. During this confrontation, Mr. Wilson confronted Mr. Richards and punched him in the head knocking him to the concrete floor. Mr. Wilson then asked 
all those present to leave and was heard shortly afterwards demanding Mr. Richards' wallet.

Mr. Thomas Cain, Mr. Wilson's cousin who had remained behind in the basement room, reported that Mr. Wilson beat Mr. Richards and that he, himself, had complied with Mr. Wilson's direction to strike the victim in the head. Approximately ten minutes later, $\mathrm{Mr}$. Wilson and Mr. Cain dragged the unconscious victim and placed him in the box of the victim's truck. Mr. Wilson then drove the victim's truck and parked it a few kilometers away. At 6am the next morning, the victim crawled from the box and was seen wandering in the street by a passerby who then called an ambulance upon seeing the condition of the victim. Mr. Richards was taken to the hospital where he remained for 2 days for treatment of a concussion and a scalp laceration. In addition, Mr. Richards noticed that his wallet and $\$ 1000$ dollars' worth of tools were missing from his truck. Mr. Wilson was arrested after a brief investigation. Mr. Wilson's account of the offence does not differ from the official record.

\section{Psychosocial Development}

Mr. Wilson is the second eldest of three children born to June Gauthier and John Wilson. Mr. Wilson's father died when Mr. Wilson was a baby and he was subsequently raised by his mother and grandparents. Other than the death of his father, Mr. Wilson's childhood was uneventful. In school, Mr. Wilson had minor behavioural and discipline issues and was assessed as having borderline intelligence. He dropped out of high school but went on to complete his High School Diploma Equivalency.

When in the community, Mr. Wilson has maintained employment as a maintenance worker. His current employer has indicated that Mr. Wilson can return to his job once released from his current sentence.

Mr. Wilson has never been able to maintain a long-term romantic relationship. In fact, his longest relationship to date lasted only a few months. Mr. Wilson does have a good relationship with his mother. She continues to support him and, should he be released, Mr. Wilson will reside with his mother. Mr. Wilson has not spoken to his siblings in some time.

\section{Criminal History}

Mr. Wilson's criminal history dates back to 1995. Mr. Wilson has 20 criminal convictions for non-violent offences including convictions for property-related offenses, failure to comply with conditions of recognizance or probation, and possession of controlled substances. Of particular concern, however, are his three convictions for robbery and his two convictions for assault (one for assault causing bodily harm and the other for aggravated assault). Mr. Wilson has served two federal sentences and numerous provincial sentences.

\section{Mental Health History and Psychiatric Diagnosis}

Based on his offense history and the examination of psychometric tests, Mr. Wilson justifies the diagnosis of: Substance use disorder 
Mr. Wilson's history of substance abuse extends to his adolescence and includes a variety of different substances including alcohol, marijuana, and crack cocaine. Alcohol and/or drugs have been a factor in several of his past criminal offences.

Mr. Wilson does not present with any other mental health diagnoses.

\section{Correctional and Rehabilitation History}

During past incarcerations, Mr. Wilson presented with minor behavioural problems (altercations with other inmates, being caught with drug paraphernalia).

During his current incarceration, Mr. Wilson presented no behavioural problems. He was able to attain his High School Equivalency. He successfully completed the five-week Anger and Emotions Management Program and improved on five of six areas targeted.

"Moderate further intervention" was recommended. Mr. Wilson also successfully completed the Offender Substance Abuse Pre-Release Program and was evaluated positively by program staff. He has indicated that he is now sober and dedicated to maintaining his sobriety in the community. He has agreed to continue to attend treatment for alcohol and drug dependence once released.

\section{Risk Assessment}

One of the most widely used tools for the prediction of future offending is the Level of Service Inventory-Revised (LSI-R). The LSI-R is a general offending tool and scores can range from 0-54. Higher scores indicate higher risk. My score for Mr. Wilson on the LSI$\mathrm{R}$ is 41 , which places him in Risk Level $4 \mathrm{~b}$ (out of a possible 5 levels). Individuals placed in Level 4b are considered Well Above Average Risk. They have many factors that contribute to their risk for future crime, some of which are chronic and severe such as $\mathrm{Mr}$. Wilson's substance abuse.

Individuals in the Well Above Average Risk category (Level 4b) have an average reoffending rate of $49 \%$ over 2 years with a possible range of $41 \%$ to $58 \%$. Individuals in this risk category require intensive monitoring when in the community to ensure compliance with supervision. They also require very significant treatment (200-300 hours). It is expected that many individuals in Level $4 \mathrm{~b}$ will lower their risk down to a Level 3, Average Risk, within a year or two after a sufficient dosage of treatment or positive life changes, or should they remain offence-free in the community for 10 to 15 years.

I also utilized the Statistical Information on Recidivism scale (SIR). The SIR is a 15-item scale with scores ranging from -27 to 33 . The categories the SIR scale provides are the reintegration potential an individual has after being released from prison. The five possible categories are: very good reintegration potential (or low risk), good potential, fair potential, fair/poor potential, or poor reintegration potential (or high risk). My score for Mr. Wilson on the SIR scale is 7, which places him in the second highest category of fair to poor reintegration potential (level 4 of 5). Other offenders with a score similar to Mr. Wilson's reoffended at rates of roughly $60 \%$ over three years. 
In addition to the above actuarial instruments, I have utilized the manual for the Historical Clinical Risk Management-20 or HCR-20, a structure of clinical guidelines for the assessment of violent recidivism. Structured clinical guidelines are lists of factors that are identified in the literature as relevant to the assessment of future risk of recidivism. Mr. Wilson's risk according to the HCR-20 was also in the high range and this rating is particularly dependent on his historical factors. Historical factors of concern include his past and present violence, substance abuse, relationship problems, and past supervision failures. There are a few risk-reducing features to consider: his positive employment history, absence of mental illness, and good support from his mother.

\section{Treatment and Management}

During his current incarceration, Mr. Wilson has shown himself to be an excellent patient and been fully cooperative with both treatment and correctional staff. Given his serious substance abuse history, it is my recommendation that he continue with his substance abuse treatment in the community. I also recommend that he continue to see a therapist for any residual anger issues.

In addition to therapeutic intervention, Mr. Wilson needs intensive supervision if he is to live in the community again. There are a number of strategies that could be used to manage his risk. Should consideration be made for community re-integration, the following is recommended: bi-weekly meetings with a parole officer, mandatory drug and alcohol testing.

\section{Overall Opinion}

Overall, Mr. Wilson is considered as well above the average offender in terms of his risk for committing future crimes at this point in time. This is not to say that his risk cannot be lowered if he is provided with an appropriate treatment plan. Based on the information above, Mr. Wilson requires an intensive treatment program (200-300 hours) targeting his substance abuse and anger issues. With appropriate treatment and intensive supervision in the community, Mr. Wilson could certainly lower his risk of reoffending substantially. One of the most important factors for Mr. Wilson will be time; it is expected that Mr. Wilson's reduction in risk will happen gradually over many years (10 years). 


\section{HIGH RISK VIGNETTE - Status Quo}

Nearly all prisoners will eventually be released. Some prisoners may be paroled which means they are released from prison to serve the last part of their sentence in the community. Their release is supervised by correction's officers and they can get some help with things like mental health and substance abuse. They also need to obey certain rules. If they break any of these rules, they could be sent back to prison for the rest of their sentence.

You are tasked with reviewing the following report which has been prepared by a registered clinician in order to help the parole board in deciding whether Mr. Darrell Wilson should be released to serve the last part of his sentence in the community. Once you have read the report, you will be asked for your opinion concerning Mr. Wilson's parole hearing.

In reading the following assessment, you can assume that the psychologist is a qualified expert and that all measures of risk used are accepted within the field.

\section{Evaluation Report}

Report written by: Dr. John Campbell

Name: Darrell Wilson

Age: 43

Offenses: Assault; Robbery

I have been asked to complete a psychological risk assessment for Mr. Darrell Wilson. Mr. Wilson is currently serving a 2.5-year sentence for assault and robbery. Mr. Wilson is now eligible for parole after serving two-thirds of his sentence in a federal institution. This report is meant to aid the parole board in making their release decision.

I met with Mr. Wilson over the course of three separate sessions. In total, I spoke with Mr. Wilson for just over 6 hours. I also had access to the following records in order to confirm information provided by Mr. Wilson: law enforcement records (e.g., arrest reports), past mental health evaluations, correctional assessments (e.g., behaviour reports from past incarcerations), and court transcripts.

\section{Current Offense}

Mr. Wilson was convicted of assault and robbery following a jury trial in January 2018. These events occurred in December 2016. Mr. Wilson had been drinking and smoking crack cocaine with a number of others in the basement of a house known to be used as a drug/party house. At some point, a confrontation occurred between Mr. Wilson and the victim, Kyle Richards. During this confrontation, Mr. Wilson confronted Mr. Richards and punched him in the head knocking him to the concrete floor. Mr. Wilson then asked 
all those present to leave and was heard shortly afterwards demanding Mr. Richards' wallet.

Mr. Thomas Cain, Mr. Wilson's cousin who had remained behind in the basement room, reported that Mr. Wilson beat Mr. Richards and that he, himself, had complied with Mr. Wilson's direction to strike the victim in the head. Approximately ten minutes later, $\mathrm{Mr}$. Wilson and Mr. Cain dragged the unconscious victim and placed him in the box of the victim's truck. Mr. Wilson then drove the victim's truck and parked it a few kilometers away. At 6 am the next morning, the victim crawled from the box and was seen wandering in the street by a passerby who then called an ambulance upon seeing the condition of the victim. Mr. Richards was taken to the hospital where he remained for 2 days for treatment of a concussion and a scalp laceration. In addition, Mr. Richards noticed that his wallet and $\$ 1000$ dollars' worth of tools were missing from his truck. Mr. Wilson was arrested after a brief investigation. Mr. Wilson's account of the offence does not differ from the official record.

\section{Psychosocial Development}

Mr. Wilson is the second eldest of three children born to June Gauthier and John Wilson. Mr. Wilson's father died when Mr. Wilson was a baby and he was subsequently raised by his mother and grandparents. Other than the death of his father, Mr. Wilson's childhood was uneventful. In school, Mr. Wilson had minor behavioural and discipline issues and was assessed as having borderline intelligence. He dropped out of high school but went on to complete his High School Diploma Equivalency.

When in the community, Mr. Wilson has maintained employment as a maintenance worker. His current employer has indicated that Mr. Wilson can return to his job once released from his current sentence.

Mr. Wilson has never been able to maintain a long-term romantic relationship. In fact, his longest relationship to date lasted only a few months. Mr. Wilson does have a good relationship with his mother. She continues to support him and, should he be released, Mr. Wilson will reside with his mother. Mr. Wilson has not spoken to his siblings in some time.

\section{Criminal History}

Mr. Wilson's criminal history dates back to 1995. Mr. Wilson has 20 criminal convictions for non-violent offences including convictions for property-related offenses, failure to comply with conditions of recognizance or probation, and possession of controlled substances. Of particular concern, however, are his three convictions for robbery and his two convictions for assault (one for assault causing bodily harm and the other for aggravated assault). Mr. Wilson has served two federal sentences and numerous provincial sentences.

\section{Mental Health History and Psychiatric Diagnosis}

Based on his offense history and the examination of psychometric tests, Mr. Wilson justifies the diagnosis of: Substance use disorder 
Mr. Wilson's history of substance abuse extends to his adolescence and includes a variety of different substances including alcohol, marijuana, and crack cocaine. Alcohol and/or drugs have been a factor in several of his past criminal offences.

Mr. Wilson does not present with any other mental health diagnoses.

\section{Correctional and Rehabilitation History}

During past incarcerations, Mr. Wilson presented with minor behavioural problems (altercations with other inmates, being caught with drug paraphernalia).

During his current incarceration, Mr. Wilson presented no behavioural problems. He was able to attain his High School Equivalency. He successfully completed the five-week Anger and Emotions Management Program and improved on five of six areas targeted. "Moderate further intervention" was recommended. Mr. Wilson also successfully completed the Offender Substance Abuse Pre-Release Program and was evaluated positively by program staff. He has indicated that he is now sober and dedicated to maintaining his sobriety in the community. He has agreed to continue to attend treatment for alcohol and drug dependence once released.

\section{Risk Assessment}

One of the most widely used tools for the prediction of future offending is the Level of Service Inventory-Revised (LSI-R). The LSI-R is a general offending tool and scores can range from 0-54. Higher scores indicate higher risk. There are five risk levels an individual may be classified into: low, low/moderate, moderate, moderate/high, and high. My score for Mr. Wilson on the LSI-R is 41, which places him in the 'high' risk category for committing any new offence. After two years, $49 \%$ of offenders with a similar score as Mr. Wilson's committed a new offence.

I also utilized the Statistical Information on Recidivism scale (SIR). The SIR is a 15-item scale with scores ranging from -27 to 33 . The categories the SIR scale provides are the reintegration potential an individual has after being released from prison. The five possible categories are: very good reintegration potential (or low risk), good potential, fair potential, fair/poor potential, or poor reintegration potential (or high risk). My score for Mr. Wilson on the SIR scale is 7, which places him in the second highest category of fair to poor reintegration potential (level 4 out of 5). Other offenders with a score similar to Mr. Wilson's reoffended at rates of roughly $60 \%$ over three years.

In addition to the above actuarial instruments, I have utilized the manual for the Historical Clinical Risk Management-20 or HCR-20, a structure of clinical guidelines for assessment of violent recidivism. Structured clinical guidelines are lists of factors that are identified in the literature as relevant to the assessment of future risk of recidivism. $\mathrm{Mr}$. Wilson's risk according to the HCR-20 was also in the high range and this rating is particularly dependent on his historical factors. Historical factors of concern include his past and present violence, substance abuse, relationship problems, and past supervision 
failures. There are a few risk-reducing features to consider: his positive employment history, absence of mental illness, and good support from his mother.

\section{Treatment and Management}

During his current incarceration, Mr. Wilson has shown himself to be an excellent patient and been fully cooperative with both treatment and correctional staff. Given his serious substance abuse history, it is my recommendation that he continue with his substance abuse treatment in the community. I also recommend that he continue to see a therapist for any residual anger issues.

In addition to therapeutic intervention, Mr. Wilson needs intensive supervision if he is to live in the community again. There are a number of strategies that could be used to manage his risk. Should consideration be made for community re-integration, the following is recommended: bi-weekly meetings with a parole officer, mandatory drug and alcohol testing.

\section{Overall Opinion}

Based on the actuarial risk tools, Mr. Wilson was placed in either the highest or second highest risk category indicating a high risk of reoffending. His potential for community reintegration was also rated as fair to poor. He has historical and unchanging factors that contribute to him being at a high risk to reoffend which include his past violent behaviour and his substance misuse. He does have some factors that reduce his likelihood of committing a new offence, which include positive employment history and support from his mother. He has generally been amenable to treatment and should continue to receive interventions that target his substance abuse. 


\section{MODERATE RISK VIGNETTE - Five-Levels}

Nearly all prisoners will eventually be released. Some prisoners may be paroled which means they are released from prison to serve the last part of their sentence in the community. Their release is supervised by correction's officers and they can get some help with things like mental health and substance abuse. They also need to obey certain rules. If they break any of these rules, they could be sent back to prison for the rest of their sentence.

You are tasked with reviewing the following report which has been prepared by a registered clinician in order to help the parole board in deciding whether Mr. Darrell Wilson should be released to serve the last part of his sentence in the community. Once you have read the report, you will be asked for your opinion concerning Mr. Wilson's parole hearing.

In reading the following assessment, you can assume that the psychologist is a qualified expert and that all measures of risk used are accepted within the field.

\section{Evaluation Report}

Report written by: Dr. John Campbell

Name: Darrell Wilson

Age: 43

Offenses: Assault; Robbery

I have been asked to complete a psychological risk assessment for Mr. Darrell Wilson. Mr. Wilson is currently serving a 2.5-year sentence for assault and robbery. Mr. Wilson is now eligible for parole after serving two-thirds of his sentence in a federal institution. This report is meant to aid the parole board in making their release decision.

I met with Mr. Wilson over the course of three separate sessions. In total, I spoke with Mr. Wilson for just over 6 hours. I also had access to the following records in order to confirm information provided by Mr. Wilson: law enforcement records (e.g., arrest reports), past mental health evaluations, correctional assessments (e.g., behaviour reports from past incarcerations), and court transcripts.

\section{Current Offense}

Mr. Wilson was convicted of assault and robbery following a jury trial in January 2018. These events occurred in December 2016. Mr. Wilson had been drinking and smoking crack cocaine with a number of others in the basement of a house known to be used as a drug/party house. At some point, a confrontation occurred between Mr. Wilson and the victim, Kyle Richards. During this confrontation, Mr. Wilson confronted Mr. Richards and punched him in the head knocking him to the concrete floor. Mr. Wilson then asked 
all those present to leave and was heard shortly afterwards demanding Mr. Richards' wallet.

Mr. Thomas Cain, Mr. Wilson's cousin who had remained behind in the basement room, reported that Mr. Wilson beat Mr. Richards and that he, himself, had complied with Mr. Wilson's direction to strike the victim in the head. Approximately ten minutes later, $\mathrm{Mr}$. Wilson and Mr. Cain dragged the unconscious victim and placed him in the box of the victim's truck. Mr. Wilson then drove the victim's truck and parked it a few kilometers away. At 6am the next morning, the victim crawled from the box and was seen wandering in the street by a passerby who then called an ambulance upon seeing the condition of the victim. Mr. Richards was taken to the hospital where he remained for 2 days for treatment of a concussion and a scalp laceration. In addition, Mr. Richards noticed that his wallet and $\$ 1000$ dollars' worth of tools were missing from his truck. Mr. Wilson was arrested after a brief investigation. Mr. Wilson's account of the offence does not differ from the official record.

\section{Psychosocial Development}

Mr. Wilson is the second eldest of three children born to June Gauthier and John Wilson. Mr. Wilson's father died when Mr. Wilson was a baby and he was subsequently raised by his mother and grandparents. Other than the death of his father, Mr. Wilson's childhood was uneventful. In school, Mr. Wilson had minor behavioural and discipline issues and was assessed as having borderline intelligence. He dropped out of high school but went on to complete his High School Diploma Equivalency.

When in the community, Mr. Wilson has maintained employment as a maintenance worker. His current employer has indicated that Mr. Wilson can return to his job once released from his current sentence.

Mr. Wilson has never been able to maintain a long-term romantic relationship. In fact, his longest relationship to date lasted only a few months. Mr. Wilson does have a good relationship with his mother. She continues to support him and, should he be released, Mr. Wilson will reside with his mother. Mr. Wilson has not spoken to his siblings in some time.

\section{Criminal History}

Mr. Wilson's criminal history dates back to 2005. Mr. Wilson has two criminal convictions for non-violent crimes (property-related offense and possession of controlled substances). Of particular concern, however, is his past conviction for assault. Mr. Wilson has served one provincial sentence for his past assault conviction. This is his first federal sentence (a sentence that is 2 years or more).

\section{Mental Health History and Psychiatric Diagnosis}

Based on his offense history and the examination of psychometric tests, Mr. Wilson justifies the diagnosis of: Substance use disorder 
Mr. Wilson's history of substance abuse extends to his adolescence and includes a variety of different substances including alcohol, marijuana, and crack cocaine. Alcohol and/or drugs have been a factor in several of his past criminal offences.

Mr. Wilson does not present with any other mental health diagnoses.

\section{Correctional and Rehabilitation History}

During past incarceration, Mr. Wilson presented with minor behavioural problems (altercations with other inmates, being caught with drug paraphernalia).

During his current incarceration, Mr. Wilson presented no behavioural problems. He was able to attain his High School Equivalency. He successfully completed the five-week Anger and Emotions Management Program and improved on five of six areas targeted. "Moderate further intervention" was recommended. Mr. Wilson also successfully completed the Offender Substance Abuse Pre-Release Program and was evaluated positively by program staff. He has indicated that he is now sober and dedicated to maintaining his sobriety in the community. He has agreed to continue to attend treatment for alcohol and drug dependence once released.

\section{Risk Assessment}

One of the most widely used tools for the prediction of future offending is the Level of Service Inventory-Revised (LSI-R). The LSI-R is a general offending tool and scores can range from 0-54. Higher scores indicate higher risk. My score for Mr. Wilson on the LSI$\mathrm{R}$ is 25, which places him in Risk Level 3 (out of a possible 5 levels). Individuals placed in Level 3 are considered Average Risk. They have one or two factors that contribute to their risk for future crime such as Mr. Wilson's substance abuse.

Individuals in the Average Risk category (Level 3) have an average reoffending rate of $18 \%$ over 2 years with a possible range of $13 \%$ to $25 \%$. Individuals in this risk category are expected to benefit from short-term monitoring when in the community to ensure compliance with supervision. They also require sufficient treatment (100-200 hours). It is expected that many individuals in Level 3 will significantly lower their risk down to a Level 2, Below Average Risk, within a year or two after a sufficient dosage of treatment or positive life changes, or should they remain offence-free in the community for 5 to 7 years.

I also utilized the Statistical Information on Recidivism scale (SIR). The SIR is a 15-item scale with scores ranging from -27 to 33 . The categories the SIR scale provides are the reintegration potential an individual has after being released from prison. The five possible categories are: very good reintegration potential (or low risk), good potential, fair potential, fair/poor potential, or poor reintegration potential (or high risk). My score for Mr. Wilson on the SIR scale is 2, which places him in the middle category of 'fair' reintegration potential (level 3 of 5). Other offenders with a score similar to Mr. Wilson's reoffended at rates of roughly $45 \%$ over three years. 
In addition to the above actuarial instruments, I have utilized the manual for the Historical Clinical Risk Management-20 or HCR-20, a structure of clinical guidelines for assessment of violent recidivism. Structured clinical guidelines are lists of factors that are identified in the literature as relevant to the assessment of future risk of recidivism. Mr. Wilson's risk according to the HCR-20 was also in the moderate range and this rating is particularly dependent on his historical factors. Historical factors of concern include his past and present violence, substance abuse, and relationship problems. There are a few risk-reducing features to consider: his positive employment history, absence of mental illness, and good support from his mother.

\section{Treatment and Management}

During his current incarceration, Mr. Wilson has shown himself to be an excellent patient and been fully cooperative with both treatment and correctional staff. Given his serious substance abuse history, it is my recommendation that he continue with his substance abuse treatment in the community. I also recommend that he continue to see a therapist for any residual anger issues.

In addition to therapeutic intervention, Mr. Wilson needs considerable supervision if he is to live in the community again. There are a number of strategies that could be used to manage his risk. Should consideration be made for community re-integration, the following is recommended: bi-weekly meetings with a parole officer, mandatory drug and alcohol testing.

\section{Overall Opinion}

Overall, Mr. Wilson is considered an average offender in terms of his risk for committing future crimes at this point in time. This is not to say that his risk cannot be lowered if he is provided with an appropriate treatment plan. Based on the information above, Mr. Wilson requires a treatment program (100-200 hours) targeting his substance abuse. With appropriate treatment and supervision in the community, Mr. Wilson could certainly lower his risk of reoffending substantially. One of the most important factors for Mr. Wilson will be time; it is expected that Mr. Wilson's reduction in risk will happen gradually over 5- 7 years. 


\section{MODERATE RISK VIGNETTE - Status Quo}

Nearly all prisoners will eventually be released. Some prisoners may be paroled which means they are released from prison to serve the last part of their sentence in the community. Their release is supervised by correction's officers and they can get some help with things like mental health and substance abuse. They also need to obey certain rules. If they break any of these rules, they could be sent back to prison for the rest of their sentence.

You are tasked with reviewing the following report which has been prepared by a registered clinician in order to help the parole board in deciding whether Mr. Darrell Wilson should be released to serve the last part of his sentence in the community. Once you have read the report, you will be asked for your opinion concerning Mr. Wilson's parole hearing.

In reading the following assessment, you can assume that the psychologist is a qualified expert and that all measures of risk used are accepted within the field.

\section{Evaluation Report}

Report written by: Dr. John Campbell

Name: Darrell Wilson

Age: 43

Offenses: Assault; Robbery

I have been asked to complete a psychological risk assessment for Mr. Darrell Wilson. Mr. Wilson is currently serving a 2.5-year sentence for assault and robbery. Mr. Wilson is now eligible for parole after serving two-thirds of his sentence in a federal institution. This report is meant to aid the parole board in making their release decision.

I met with Mr. Wilson over the course of three separate sessions. In total, I spoke with Mr. Wilson for just over 6 hours. I also had access to the following records in order to confirm information provided by Mr. Wilson: law enforcement records (e.g., arrest reports), past mental health evaluations, correctional assessments (e.g., behaviour reports from past incarcerations), and court transcripts.

\section{Current Offense}

Mr. Wilson was convicted of assault and robbery following a jury trial in January 2018. These events occurred in December 2016. Mr. Wilson had been drinking and smoking crack cocaine with a number of others in the basement of a house known to be used as a drug/party house. At some point, a confrontation occurred between Mr. Wilson and the victim, Kyle Richards. During this confrontation, Mr. Wilson confronted Mr. Richards and punched him in the head knocking him to the concrete floor. Mr. Wilson then asked 
all those present to leave and was heard shortly afterwards demanding Mr. Richards' wallet.

Mr. Thomas Cain, Mr. Wilson's cousin who had remained behind in the basement room, reported that Mr. Wilson beat Mr. Richards and that he, himself, had complied with Mr. Wilson's direction to strike the victim in the head. Approximately ten minutes later, $\mathrm{Mr}$. Wilson and Mr. Cain dragged the unconscious victim and placed him in the box of the victim's truck. Mr. Wilson then drove the victim's truck and parked it a few kilometers away. At 6am the next morning, the victim crawled from the box and was seen wandering in the street by a passerby who then called an ambulance upon seeing the condition of the victim. Mr. Richards was taken to the hospital where he remained for 2 days for treatment of a concussion and a scalp laceration. In addition, Mr. Richards noticed that his wallet and $\$ 1000$ dollars' worth of tools were missing from his truck. Mr. Wilson was arrested after a brief investigation. Mr. Wilson's account of the offence does not differ from the official record.

\section{Psychosocial Development}

Mr. Wilson is the second eldest of three children born to June Gauthier and John Wilson. Mr. Wilson's father died when Mr. Wilson was a baby and he was subsequently raised by his mother and grandparents. Other than the death of his father, Mr. Wilson's childhood was uneventful. In school, Mr. Wilson had minor behavioural and discipline issues and was assessed as having borderline intelligence. He dropped out of high school but went on to complete his High School Diploma Equivalency.

When in the community, Mr. Wilson has maintained employment as a maintenance worker. His current employer has indicated that Mr. Wilson can return to his job once released from his current sentence.

Mr. Wilson has never been able to maintain a long-term romantic relationship. In fact, his longest relationship to date lasted only a few months. Mr. Wilson does have a good relationship with his mother. She continues to support him and, should he be released, Mr. Wilson will reside with his mother. Mr. Wilson has not spoken to his siblings in some time.

\section{Criminal History}

Mr. Wilson's criminal history dates back to 2005. Mr. Wilson has two criminal convictions for non-violent crimes (property-related offense and possession of controlled substances). Of particular concern, however, is his past conviction for assault. Mr. Wilson has served one provincial sentence for his past assault conviction. This is his first federal sentence (a sentence that is 2 years or more).

\section{Mental Health History and Psychiatric Diagnosis}

Based on his offense history and the examination of psychometric tests, Mr. Wilson justifies the diagnosis of: Substance use disorder 
Mr. Wilson's history of substance abuse extends to his adolescence and includes a variety of different substances including alcohol, marijuana, and crack cocaine. Alcohol and/or drugs have been a factor in several of his past criminal offences.

Mr. Wilson does not present with any other mental health diagnoses.

\section{Correctional and Rehabilitation History}

During past incarceration, Mr. Wilson presented with minor behavioural problems (altercations with other inmates, being caught with drug paraphernalia).

During his current incarceration, Mr. Wilson presented no behavioural problems. He was able to attain his High School Equivalency. He successfully completed the five-week Anger and Emotions Management Program and improved on five of six areas targeted. "Moderate further intervention" was recommended. Mr. Wilson also successfully completed the Offender Substance Abuse Pre-Release Program and was evaluated positively by program staff. He has indicated that he is now sober and dedicated to maintaining his sobriety in the community. He has agreed to continue to attend treatment for alcohol and drug dependence once released.

\section{Risk Assessment}

One of the most widely used tools for the prediction of future offending is the Level of Service Inventory-Revised (LSI-R). The LSI-R is a general offending tool and scores can range from 0-54. Higher scores indicate higher risk. There are five risk levels an individual may be classified into: low, low/moderate, moderate, moderate/high, and high. My score for Mr. Wilson on the LSI-R is 25, which places him in the 'moderate' risk category for committing any new offence. After two years, $18 \%$ of offenders with a similar score as Mr. Wilson committed a new offence.

I also utilized the Statistical Information on Recidivism scale (SIR). The SIR is a 15-item scale with scores ranging from -27 to 33 . The categories the SIR scale provides are the reintegration potential an individual has after being released from prison. The five possible categories are: very good reintegration potential (or low risk), good potential, fair potential, fair/poor potential, or poor reintegration potential (or high risk). My score for Mr. Wilson on the SIR scale is 2, which places him in the middle category of 'fair' reintegration potential (level 3 of 5). Other offenders with a score similar to Mr. Wilson's reoffended at rates of roughly $45 \%$ over three years.

In addition to the above actuarial instruments, I have utilized the manual for the Historical Clinical Risk Management-20 or HCR-20, a structure of clinical guidelines for the assessment of violent recidivism. Structured clinical guidelines are lists of factors that are identified in the literature as relevant to the assessment of future risk of recidivism. Mr. Wilson's risk according to the HCR-20 was also in the moderate range and this rating is particularly dependent on his historical factors. Historical factors of concern include his past and present violence, substance abuse, and relationship problems. There are a few risk-reducing features to consider: his positive employment history, absence of mental illness, and good support from his mother. 


\section{Treatment and Management}

During his current incarceration, Mr. Wilson has shown himself to be an excellent patient and been fully cooperative with both treatment and correctional staff. Given his serious substance abuse history, it is my recommendation that he continue with his substance abuse treatment in the community. I also recommend that he continue to see a therapist for any residual anger issues.

In addition to therapeutic intervention, Mr. Wilson needs considerable supervision if he is to live in the community again. There are a number of strategies that could be used to manage his risk. Should consideration be made for community re-integration, the following is recommended: bi-weekly meetings with a parole officer, mandatory drug and alcohol testing.

\section{Overall Opinion}

Based on the actuarial risk tools, Mr. Wilson was placed in the moderate risk category indicating a moderate risk of reoffending. His potential for community reintegration was also rated as fair. He has historical and unchanging factors that contribute to him being at a moderate risk to reoffend which include his substance misuse. He does have some factors that reduce his likelihood of committing a new offence, which include positive employment history and support from his mother. He has generally been amenable to treatment and should continue to receive interventions that target his substance abuse. 


\section{LOW RISK VIGNETTE - Five-Levels}

Nearly all prisoners will eventually be released. Some prisoners may be paroled which means they are released from prison to serve the last part of their sentence in the community. Their release is supervised by correction's officers and they can get some help with things like mental health and substance abuse. They also need to obey certain rules. If they break any of these rules, they could be sent back to prison for the rest of their sentence.

You are tasked with reviewing the following report which has been prepared by a registered clinician in order to help the parole board in deciding whether Mr. Darrell Wilson should be released to serve the last part of his sentence in the community. Once you have read the report, you will be asked for your opinion concerning Mr. Wilson's parole hearing.

In reading the following assessment, you can assume that the psychologist is a qualified expert and that all measures of risk used are accepted within the field.

\section{Evaluation Report}

Report written by: Dr. John Campbell

Name: Darrell Wilson

Age: 43

Offenses: Assault; Robbery

I have been asked to complete a psychological risk assessment for Mr. Darrell Wilson. Mr. Wilson is currently serving a 2.5-year sentence for assault and robbery. Mr. Wilson is now eligible for parole after serving two-thirds of his sentence in a federal institution. This report is meant to aid the parole board in making their release decision.

I met with Mr. Wilson over the course of three separate sessions. In total, I spoke with Mr. Wilson for just over 6 hours. I also had access to the following records in order to confirm information provided by Mr. Wilson: law enforcement records (e.g., arrest reports), past mental health evaluations, correctional assessments (e.g., behaviour reports from past incarcerations), and court transcripts.

\section{Current Offense}

Mr. Wilson was convicted of assault and robbery following a jury trial in January 2018. These events occurred in December 2016. Mr. Wilson had been drinking and smoking crack cocaine with a number of others in the basement of a house known to be used as a drug/party house. At some point, a confrontation occurred between Mr. Wilson and the victim, Kyle Richards. During this confrontation, Mr. Wilson confronted Mr. Richards and punched him in the head knocking him to the concrete floor. Mr. Wilson then asked 
all those present to leave and was heard shortly afterwards demanding Mr. Richards' wallet.

Mr. Thomas Cain, Mr. Wilson's cousin who had remained behind in the basement room, reported that Mr. Wilson beat Mr. Richards and that he, himself, had complied with Mr. Wilson's direction to strike the victim in the head. Approximately ten minutes later, $\mathrm{Mr}$. Wilson and Mr. Cain dragged the unconscious victim and placed him in the box of the victim's truck. Mr. Wilson then drove the victim's truck and parked it a few kilometers away. At 6am the next morning, the victim crawled from the box and was seen wandering in the street by a passerby who then called an ambulance upon seeing the condition of the victim. Mr. Richards was taken to the hospital where he remained for 2 days for treatment of a concussion and a scalp laceration. In addition, Mr. Richards noticed that his wallet and $\$ 1000$ dollars' worth of tools were missing from his truck. Mr. Wilson was arrested after a brief investigation. Mr. Wilson's account of the offence does not differ from the official record.

\section{Psychosocial Development}

Mr. Wilson is the second eldest of three children born to June Gauthier and John Wilson. Mr. Wilson's father died when Mr. Wilson was a baby and he was subsequently raised by his mother and grandparents. Other than the death of his father, Mr. Wilson's childhood was uneventful. In school, Mr. Wilson had minor behavioural and discipline issues and was assessed as having borderline intelligence. He dropped out of high school but went on to complete his High School Diploma Equivalency.

When in the community, Mr. Wilson has maintained employment as a maintenance worker. His current employer has indicated that Mr. Wilson can return to his job once released from his current sentence.

Mr. Wilson has never been able to maintain a long-term romantic relationship. In fact, his longest relationship to date lasted only a few months. Mr. Wilson does have a good relationship with his mother. She continues to support him and, should he be released, Mr. Wilson will reside with his mother. Mr. Wilson has not spoken to his siblings in some time.

\section{Criminal History}

Mr. Wilson does not have a criminal history. The current offenses represent the first time that he comes into contact with the criminal justice system. This is his first federal sentence (a sentence that is 2 years or more).

\section{Mental Health History and Psychiatric Diagnosis}

Based on his offense history and the examination of psychometric tests, Mr. Wilson justifies the diagnosis of: Substance use disorder

Mr. Wilson's history of substance abuse extends to his adolescence and includes a variety of different substances including alcohol, marijuana, and crack cocaine. Alcohol and/or drugs were a factor in his current offences. 
Mr. Wilson does not present with any other mental health diagnoses.

\section{Correctional and Rehabilitation History}

During his current incarceration, Mr. Wilson presented no behavioural problems. He was able to attain his High School Equivalency. He successfully completed the five-week Anger and Emotions Management Program and improved on five of six areas targeted. "Moderate further intervention" was recommended. Mr. Wilson also successfully completed the Offender Substance Abuse Pre-Release Program and was evaluated positively by program staff. He has indicated that he is now sober and dedicated to maintaining his sobriety in the community. He has agreed to continue to attend treatment for alcohol and drug dependence once released.

\section{Risk Assessment}

One of the most widely used tools for the prediction of future offending is the Level of Service Inventory-Revised (LSI-R). The LSI-R is a general offending tool and scores can range from 0-54. Higher scores indicate higher risk. My score for Mr. Wilson on the LSI$\mathrm{R}$ is 7, which places him in Risk Level 1 (out of a possible 5 levels). Individuals placed in Level 1 are considered Very Low Risk. They have very few factors that contribute to their risk for future crime.

Individuals in the Very Low Risk category (Level 1) have an average reoffending rate of $3 \%$ over 2 years with a possible range of $2 \%$ to $5 \%$. Individuals in this risk category are expected to comply with conditions of community supervision. They do not require treatment but may need referrals to community services and programs. It is expected that the majority of individuals in Level 1 will desist from crime completely, even without a correctional response.

I also utilized the Statistical Information on Recidivism scale (SIR). The SIR is a 15-item scale with scores ranging from -27 to 33 . The categories the SIR scale provides are the reintegration potential an individual has after being released from prison. The five possible categories are: very good reintegration potential (or low risk), good potential, fair potential, fair/poor potential, or poor reintegration potential (or high risk). My score for Mr. Wilson on the SIR scale is -4 , which places him in the lowest category of 'good' reintegration potential (level 1 of 5). Other offenders with a score similar to Mr. Wilson's reoffended at rates of roughly $32 \%$ over three years.

In addition to the above actuarial instruments, I have utilized the manual for the Historical Clinical Risk Management-20 or HCR-20, a structure of clinical guidelines for the assessment of violent recidivism. Structured clinical guidelines are lists of factors that are identified in the literature as relevant to the assessment of future risk of recidivism. Mr. Wilson's risk according to the HCR-20 was also in the low range. Historical factors of concern include his substance abuse and relationship problems. There are a few riskreducing features to consider: his positive employment history, absence of mental illness, and good support from his mother. 


\section{Treatment and Management}

During his current incarceration, Mr. Wilson has shown himself to be an excellent patient and been fully cooperative with both treatment and correctional staff. Given his serious substance abuse history, it is my recommendation that he continue with his substance abuse treatment in the community. I also recommend that he continue to see a therapist for any residual anger issues.

In addition to therapeutic intervention, Mr. Wilson needs minimal supervision if he is to live in the community again. There are a number of strategies that could be used to manage his risk. Should consideration be made for community re-integration, the following is recommended: bi-weekly meetings with a parole officer, mandatory drug and alcohol testing.

\section{Overall Opinion}

Overall, Mr. Wilson is considered as well below the average offender in terms of his risk for committing future crimes at this point in time. Based on the information above, Mr. Wilson requires minimal treatment intervention. With access to appropriate community programs to help in his reintegration, Mr. Wilson is expected to desist from criminal behaviour over the next 1-2 years. 


\section{LOW RISK VIGNETTE - Status Quo}

Nearly all prisoners will eventually be released. Some prisoners may be paroled which means they are released from prison to serve the last part of their sentence in the community. Their release is supervised by correction's officers and they can get some help with things like mental health and substance abuse. They also need to obey certain rules. If they break any of these rules, they could be sent back to prison for the rest of their sentence.

You are tasked with reviewing the following report which has been prepared by a registered clinician in order to help the parole board in deciding whether Mr. Darrell Wilson should be released to serve the last part of his sentence in the community. Once you have read the report, you will be asked for your opinion concerning Mr. Wilson's parole hearing.

In reading the following assessment, you can assume that the psychologist is a qualified expert and that all measures of risk used are accepted within the field.

\section{Evaluation Report}

Report written by: Dr. John Campbell

Name: Darrell Wilson

Age: 43

Offenses: Assault; Robbery

I have been asked to complete a psychological risk assessment for Mr. Darrell Wilson. Mr. Wilson is currently serving a 2.5-year sentence for assault and robbery. Mr. Wilson is now eligible for parole after serving two-thirds of his sentence in a federal institution. This report is meant to aid the parole board in making their release decision.

I met with Mr. Wilson over the course of three separate sessions. In total, I spoke with Mr. Wilson for just over 6 hours. I also had access to the following records in order to confirm information provided by Mr. Wilson: law enforcement records (e.g., arrest reports), past mental health evaluations, correctional assessments (e.g., behaviour reports from past incarcerations), and court transcripts.

\section{Current Offense}

Mr. Wilson was convicted of assault and robbery following a jury trial in January 2018. These events occurred in December 2016. Mr. Wilson had been drinking and smoking crack cocaine with a number of others in the basement of a house known to be used as a drug/party house. At some point, a confrontation occurred between Mr. Wilson and the victim, Kyle Richards. During this confrontation, Mr. Wilson confronted Mr. Richards and punched him in the head knocking him to the concrete floor. Mr. Wilson then asked 
all those present to leave and was heard shortly afterwards demanding Mr. Richards' wallet.

Mr. Thomas Cain, Mr. Wilson's cousin who had remained behind in the basement room, reported that Mr. Wilson beat Mr. Richards and that he, himself, had complied with Mr. Wilson's direction to strike the victim in the head. Approximately ten minutes later, $\mathrm{Mr}$. Wilson and Mr. Cain dragged the unconscious victim and placed him in the box of the victim's truck. Mr. Wilson then drove the victim's truck and parked it a few kilometers away. At 6am the next morning, the victim crawled from the box and was seen wandering in the street by a passerby who then called an ambulance upon seeing the condition of the victim. Mr. Richards was taken to the hospital where he remained for 2 days for treatment of a concussion and a scalp laceration. In addition, Mr. Richards noticed that his wallet and $\$ 1000$ dollars' worth of tools were missing from his truck. Mr. Wilson was arrested after a brief investigation. Mr. Wilson's account of the offence does not differ from the official record.

\section{Psychosocial Development}

Mr. Wilson is the second eldest of three children born to June Gauthier and John Wilson. Mr. Wilson's father died when Mr. Wilson was a baby and he was subsequently raised by his mother and grandparents. Other than the death of his father, Mr. Wilson's childhood was uneventful. In school, Mr. Wilson had minor behavioural and discipline issues and was assessed as having borderline intelligence. He dropped out of high school but went on to complete his High School Diploma Equivalency.

When in the community, Mr. Wilson has maintained employment as a maintenance worker. His current employer has indicated that Mr. Wilson can return to his job once released from his current sentence.

Mr. Wilson has never been able to maintain a long-term romantic relationship. In fact, his longest relationship to date lasted only a few months. Mr. Wilson does have a good relationship with his mother. She continues to support him and, should he be released, Mr. Wilson will reside with his mother. Mr. Wilson has not spoken to his siblings in some time.

\section{Criminal History}

Mr. Wilson does not have a criminal history. The current offenses represent the first time that he comes into contact with the criminal justice system. This is his first federal sentence (a sentence that is 2 years or more).

\section{Mental Health History and Psychiatric Diagnosis}

Based on his offense history and the examination of psychometric tests, Mr. Wilson justifies the diagnosis of: Substance use disorder

Mr. Wilson's history of substance abuse extends to his adolescence and includes a variety of different substances including alcohol, marijuana, and crack cocaine. Alcohol and/or drugs were a factor in his current offences. 
Mr. Wilson does not present with any other mental health diagnoses.

\section{Correctional and Rehabilitation History}

During his current incarceration, Mr. Wilson presented no behavioural problems. He was able to attain his High School Equivalency. He successfully completed the five-week Anger and Emotions Management Program and improved on five of six areas targeted. "Moderate further intervention" was recommended. Mr. Wilson also successfully completed the Offender Substance Abuse Pre-Release Program and was evaluated positively by program staff. He has indicated that he is now sober and dedicated to maintaining his sobriety in the community. He has agreed to continue to attend treatment for alcohol and drug dependence once released.

\section{Risk Assessment}

One of the most widely used tools for the prediction of future offending is the Level of Service Inventory-Revised (LSI-R). The LSI-R is a general offending tool and scores can range from 0-43. Higher scores indicate higher risk. There are five risk levels an individual may be classified into: low, low/moderate, moderate, moderate/high, and high. My score for Mr. Wilson on the LSI-R is 7, which places him in the 'low' risk category for committing any new offence. After two years, $3 \%$ of offenders with a similar score as Mr. Wilson committed a new offence.

I also utilized the Statistical Information on Recidivism scale (SIR). The SIR is a 15-item scale with scores ranging from -27 to 33 . The categories the SIR scale provides are the reintegration potential an individual has after being released from prison. The five possible categories are: very good reintegration potential (or low risk), good potential, fair potential, fair/poor potential, or poor reintegration potential (or high risk). My score for Mr. Wilson on the SIR scale is -4 , which places him in the second lowest category of 'good' reintegration potential (level 2 of 5). Other offenders with a score similar to Mr. Wilson's reoffended at rates of roughly $32 \%$ over three years.

In addition to the above actuarial instruments, I have utilized the manual for the Historical Clinical Risk Management-20 or HCR-20, a structure of clinical guidelines for the assessment of violent recidivism. Structured clinical guidelines are lists of factors that are identified in the literature as relevant to the assessment of future risk of recidivism. Mr. Wilson's risk according to the HCR-20 was also in the low range. Historical factors of concern include his substance abuse and relationship problems. There are a few riskreducing features to consider: his positive employment history, absence of mental illness, and good support from his mother.

\section{Treatment and Management}

During his current incarceration, Mr. Wilson has shown himself to be an excellent patient and been fully cooperative with both treatment and correctional staff. Given his serious substance abuse history, it is my recommendation that he continue with his substance abuse treatment in the community. I also recommend that he continue to see a therapist for any residual anger issues. 
In addition to therapeutic intervention, Mr. Wilson needs minimal supervision if he is to live in the community again. There are a number of strategies that could be used to manage his risk. Should consideration be made for community re-integration, the following is recommended: bi-weekly meetings with a parole officer, mandatory drug and alcohol testing.

\section{Overall Opinion}

Based on the actuarial risk tools, Mr. Wilson was placed in the lowest or second lowest risk category indicating a low risk of reoffending. His potential for community reintegration was also rated as good. He has historical factors that contribute to him being at a low risk to reoffend which include his substance misuse. He does have many factors that reduce his likelihood of committing a new offence, which include positive employment history and support from his mother. He has been amenable to treatment and should continue to receive interventions that target his substance abuse. 


\section{Appendix C: Eligibility, Demographics, Validity Checks, and Outcome Variables}

\section{Eligibility:}

Are you 18 years of age or older?

- Yes

- No

Can you read and write in English?

- Yes

- No

\section{Demographics:}

What is your current age?

- $\quad$ Type box, 3 characters

What gender do you identify with?

- Female

- Male

- Non-binary

- Other

- Prefer not to say

What is your racial/ethnic background?

- Asian

- Black

- East Indian

- Hispanic/Latinx

- Indigenous

- Middle Eastern

- White/Caucasian

- Other:

What is the highest level of education you have completed?

- Elementary school

- Secondary/high school

- College

- Bachelor's degree

- Master's degree 
- Professional degree/doctorate

Do you have a background in law or legal studies?

- Yes

- No

Do you have a background in psychology?

- Yes

- No

Do you use risk assessments in your professional life?

- Yes

- No

\section{Validity checks:}

Captcha (participants will have to respond to a captcha)

Displayed after the scenario:

What crime was Mr. Wilson most recently charged with?

- Murder

- Sexual assault

- Robbery

What psychiatric disorder was Mr. Wilson diagnosed with?

- Schizophrenia

- Substance use disorder

- Bipolar disorder

Displayed at 2 points in the survey:

- This question is meant to ensure that the survey software is working correctly. Please answer 3 ( 1 to 5 answer choices)

\section{Risk and Treatment relevant outcomes:}

Would you grant Mr. Wilson parole?

- Yes

- No

How confident are you in your parole decision? 
- $0-100 \%$

What do you believe Mr. Wilson's risk level is?

- Low

- Low-moderate

- Moderate

- Moderate-high

- High

Is Mr. Wilson less likely or more likely than the average offender to commit a new crime?

- Less likely

- More likely

- About the same

Will Mr. Wilson commit a new offence in the next two years?

- Yes

- No

What is the likelihood that Mr. Wilson will commit a new crime in the next two years?

- $0-100 \%$

How comfortable would you be if Mr. Wilson was released?

- $0-100 \%$

How likely is Mr. Wilson to comply with his parole conditions?

- 1 - very unlikely

- 5 - very likely

How likely is Mr. Wilson to benefit from rehabilitation/treatment?

- 1 - very unlikely

- 5 - very likely

How likely is Mr. Wilson to lower his risk of reoffending over the next few years?

- 1 - very unlikely

- 5 - very likely

How likely is Mr. Wilson to stay crime free for the next five years?

- 1 - very unlikely 
- 5 - very likely

How likely is Mr. Wilson to desist from crime completely?

- 1 - very unlikely

- 5 - very likely

How understandable did you find the information in the risk assessment?

- 1 - very difficult to understand

- 5 - very easy to understand

Did you have enough information to determine Mr. Wilson's reoffending risk?

- Yes

- No

Did you have enough information to determine Mr. Wilson's parole decision?

- Yes

- No

How important was the following information in making your decisions where $1=$ not at all important and $5=$ very important.

\begin{tabular}{|c|c|c|c|c|c|}
\hline Information & 1 & 2 & 3 & 4 & 5 \\
\hline Severity of the current offence & & & & & \\
\hline Level of victim injury during the current offence & & & & & \\
\hline Criminal history information & & & & & \\
\hline Treatment history information & & & & & \\
\hline Strength factors listed (e.g., good employment) & & & & & \\
\hline Risk factors listed (e.g., substance abuse) & & & & & \\
\hline Risk assessment overall & & & & & \\
\hline Information from the LSI-R & & & & & \\
\hline Information from the SIR & & & & & \\
\hline Information from the HCR-20 & & & & & \\
\hline Overall opinion provided at end of risk assessment & & & & & \\
\hline Other: & & & & & \\
\hline Other: & & & & & \\
\hline Other: & & & & & \\
\hline
\end{tabular}

Is there other information that could have been provided to make your decisions about Mr. Wilson easier?

- Type box 


\section{Appendix D: Recruitment Notice}

\section{PARTICIPANTS NEEDED FOR A STUDY ON PAROLE DECISION MAKING}

Testing a new non-arbitrary system for risk communication.

We are conducting a study to determine if different ways of presenting information in a risk assessment report results in differences in risk decisions related to a parole case.

\section{What is involved?}

- Read a 4-page risk assessment about a mock offender

- Complete a short questionnaire about your demographic information (e.g. age, gender, ethnic background)

- Complete a questionnaire about the case you just read; making decisions about whether you think the offender should be granted parole

\section{How long does it take?}

The study should take roughly 15-20 minutes to complete and is completed entirely online.

\section{Do I get anything for participating?}

If you provide your email address, you will be entered to win a $\$ 100$ Amazon gift card. Your email address will not be associated with your responses in any way. The information will only be used to contact you if you win.

\section{Who are the researchers?}

Meghan Garvey (Principle Researcher), Julie Blais (Faculty Supervisor)

\section{What if $I$ have questions?}

Please contact the Principle Researcher, Meghan Garvey, at meghan.garvey@carleton.ca

\section{How do I participate?}

Click on the link to access the online study:

Ethics: The ethics protocol for this project was reviewed and cleared by the Carleton University Research Ethics Board-B (Clearance \#: 112785) 


\section{Appendix E: Varying Information Across Mock Risk Assessments}

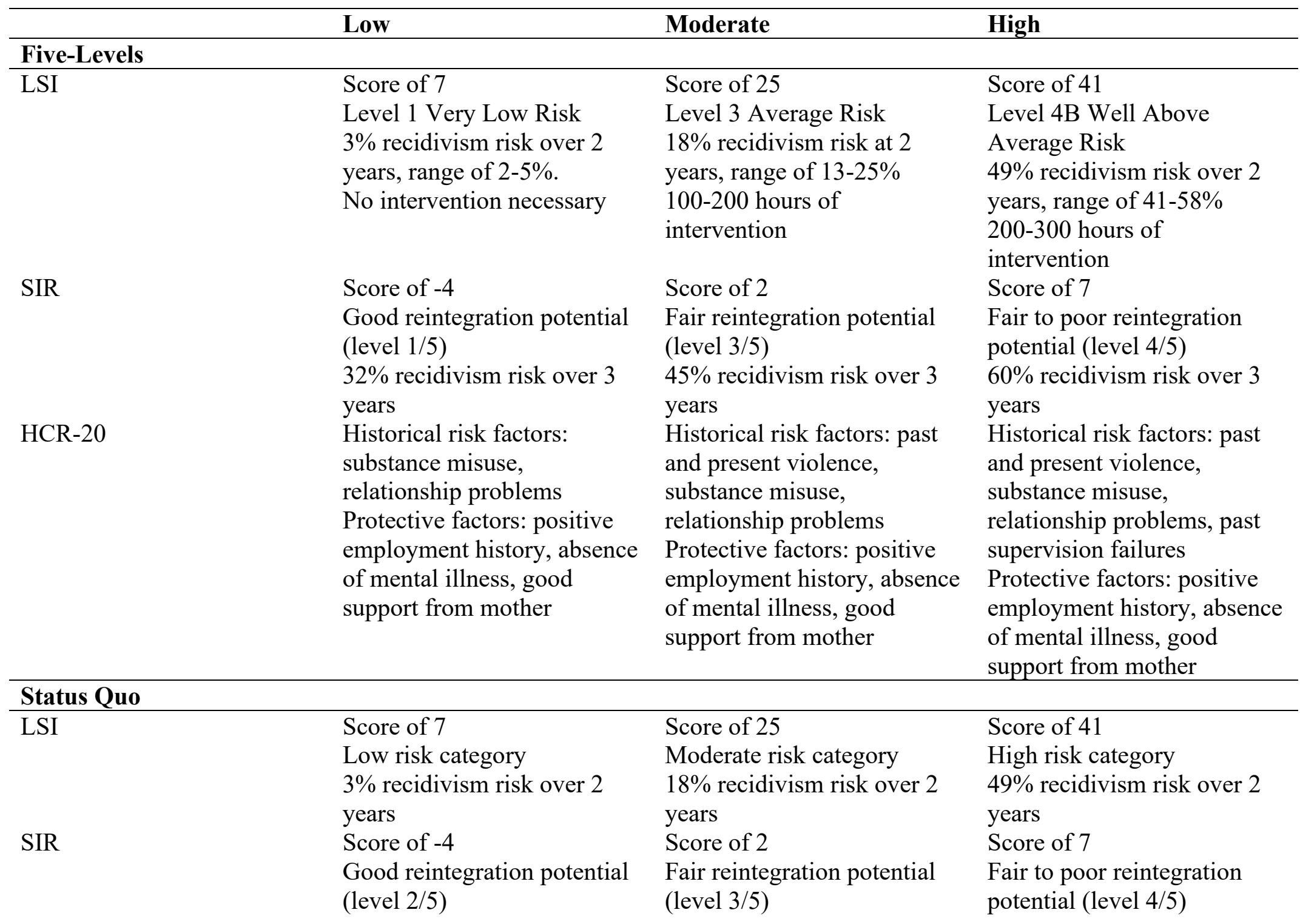




\begin{tabular}{|c|c|c|c|}
\hline HCR-20 & $\begin{array}{l}32 \% \text { recidivism risk over } 3 \\
\text { years } \\
\text { Historical risk factors: } \\
\text { substance misuse, } \\
\text { relationship problems } \\
\text { Protective factors: positive } \\
\text { employment history, absence } \\
\text { of mental illness, good } \\
\text { support from mother }\end{array}$ & $\begin{array}{l}45 \% \text { recidivism risk over } 3 \\
\text { years } \\
\text { Historical risk factors: past } \\
\text { and present violence, } \\
\text { substance misuse, } \\
\text { relationship problems } \\
\text { Protective factors: positive } \\
\text { employment history, absence } \\
\text { of mental illness, good } \\
\text { support from mother }\end{array}$ & $\begin{array}{l}60 \% \text { recidivism risk over } 3 \\
\text { years } \\
\text { Historical risk factors: past } \\
\text { and present violence, } \\
\text { substance misuse, } \\
\text { relationship problems, past } \\
\text { supervision failures } \\
\text { Protective factors: positive } \\
\text { employment history, absence } \\
\text { of mental illness, good } \\
\text { support from mother }\end{array}$ \\
\hline \multicolumn{4}{|c|}{ Criminal History } \\
\hline & $\begin{array}{l}\text { No criminal history } \\
\text { Index offence is first }\end{array}$ & $\begin{array}{l}\text { Criminal history dating back } \\
\text { to } 2005 \\
\text { Two criminal convictions for } \\
\text { non-violent crimes } \\
\text { One past assault conviction } \\
\text { Index offence is first federal } \\
\text { sentence }\end{array}$ & $\begin{array}{l}\text { Criminal history dating back } \\
\text { to } 1995 \\
20 \text { criminal convictions for } \\
\text { non-violent crimes } \\
3 \text { convictions for robbery, } 2 \\
\text { for assault } \\
2 \text { federal sentences } \\
\text { Numerous provincial } \\
\text { sentences }\end{array}$ \\
\hline \multicolumn{4}{|c|}{ Correctional History } \\
\hline & No behavioural problems & $\begin{array}{l}\text { Minor behavioural problems } \\
\text { during previous incarceration } \\
\text { periods } \\
\text { No behavioural problems } \\
\text { during current incarceration }\end{array}$ & $\begin{array}{l}\text { Minor behavioural problems } \\
\text { during previous incarceration } \\
\text { periods } \\
\text { No behavioural problems } \\
\text { during current incarceration }\end{array}$ \\
\hline \multicolumn{4}{|c|}{$\begin{array}{l}\text { Treatment and } \\
\text { Management }\end{array}$} \\
\hline & $\begin{array}{l}\text { Minimal supervision } \\
\text { recommended }\end{array}$ & $\begin{array}{l}\text { Considerable supervision } \\
\text { recommended }\end{array}$ & $\begin{array}{l}\text { Intensive supervision } \\
\text { recommended }\end{array}$ \\
\hline
\end{tabular}

